\title{
Sensitivities and uncertainties of modeled ground temperatures in mountain environments
}

\author{
S. Gubler, S. Endrizzi, S. Gruber, and R. S. Purves \\ Department of Geography, University of Zurich, Zurich, Switzerland
}

Correspondence to: S. Gubler (stefanie.gubler@geo.uzh.ch)

Received: 19 December 2012 - Published in Geosci. Model Dev. Discuss.: 6 February 2013

Revised: 27 June 2013 - Accepted: 12 July 2013 - Published: 23 August 2013

\begin{abstract}
Model evaluation is often performed at few locations due to the lack of spatially distributed data. Since the quantification of model sensitivities and uncertainties can be performed independently from ground truth measurements, these analyses are suitable to test the influence of environmental variability on model evaluation. In this study, the sensitivities and uncertainties of a physically based mountain permafrost model are quantified within an artificial topography. The setting consists of different elevations and exposures combined with six ground types characterized by porosity and hydraulic properties. The analyses are performed for a combination of all factors, that allows for quantification of the variability of model sensitivities and uncertainties within a whole modeling domain.
\end{abstract}

We found that model sensitivities and uncertainties vary strongly depending on different input factors such as topography or different soil types. The analysis shows that model evaluation performed at single locations may not be representative for the whole modeling domain. For example, the sensitivity of modeled mean annual ground temperature to ground albedo ranges between 0.5 and $4{ }^{\circ} \mathrm{C}$ depending on elevation, aspect and the ground type. South-exposed inclined locations are more sensitive to changes in ground albedo than north-exposed slopes since they receive more solar radiation. The sensitivity to ground albedo increases with decreasing elevation due to shorter duration of the snow cover. The sensitivity in the hydraulic properties changes considerably for different ground types: rock or clay, for instance, are not sensitive to uncertainties in the hydraulic properties, while for gravel or peat, accurate estimates of the hydraulic properties significantly improve modeled ground temperatures. The discretization of ground, snow and time have an impact on modeled mean annual ground temperature (MAGT) that cannot be neglected (more than $1{ }^{\circ} \mathrm{C}$ for several discretization parameters). We show that the temporal resolution should be at least $1 \mathrm{~h}$ to ensure errors less than $0.2^{\circ} \mathrm{C}$ in modeled MAGT, and the uppermost ground layer should at most be $20 \mathrm{~mm}$ thick.

Within the topographic setting, the total parametric output uncertainties expressed as the length of the $95 \%$ uncertainty interval of the Monte Carlo simulations range from 0.5 to $1.5^{\circ} \mathrm{C}$ for clay and silt, and ranges from 0.5 to around $2.4^{\circ} \mathrm{C}$ for peat, sand, gravel and rock. These uncertainties are comparable to the variability of ground surface temperatures measured within $10 \mathrm{~m} \times 10 \mathrm{~m}$ grids in Switzerland. The increased uncertainties for sand, peat and gravel are largely due to their sensitivity to the hydraulic conductivity.

\section{Introduction}

Models are important tools for investigating natural processes and providing scenarios relating to future environments. Physically based or empirical models can predict spatial or temporal variation of measured attributes and related phenomena of interest, and derived products may serve as a basis for political or economical decisions. Since every model is an abstraction and simplification of reality, and since therefore model outputs are strongly dependent on the modeler's perception of the system, any model must in a first step be evaluated for its fit to an intended purpose (Rykiel, 1996). Model evaluation forms an important part of the development process (e.g., Beven, 1993; Gupta et al., 2005). It aims at (a) determining the degree of accordance of a model output with the respective measured quantity (e.g., Rykiel, 1996; Beck et al., 1997; Anderson and Bates, 2001; 
Stow et al., 2009), (b) quantifying the related model uncertainty (e.g., Beck, 1987; Beven and Binley, 1992; Beven, 1993; Davis and Keller, 1997; Crosetto and Tarantola, 2001), (c) identifying parameters and input variables that account for the largest parts of this uncertainty (e.g., Cukier et al., 1977; Sobol, 1993; Saltelli et al., 2004, 2008) and (d) eventually calibrating the model to local conditions (e.g., Beven and Binley, 1992; Chen et al., 2000; Gupta et al., 2005).

Uncertainties and errors come from processes that are not represented in the model, unknown physical properties, errors in input data, numerical errors and the modeler's perception when selecting the processes to be represented, among others (Gupta et al., 2005). Uncertainty can be defined as limits in modeling due to lack of knowledge (e.g., unknown physical properties), while errors may arise from numerical approximations, for example (AIAA, 1998).

Models are often applied to make predictions for large spatial areas. However, model evaluation is typically restricted to only one or, in the best case, a few evaluation points due to lack of observed data for validation. In turn, this implicitly assumes that validation at a single point suffices to inform on decisions about model performance in different environmental conditions because the model is physically based (and thus representativity at one point implies representativity over a domain). However, the implications of this assumption when modeling phenomena in highly variable terrain or over long distances has been the subject of limited research. This paper is focused on a sensitivity and uncertainty analysis of a physically based mountain permafrost model to serve as a case study for examining the role of environmental variability in model evaluation.

The validity of a model cannot be determined based only on sensitivity and uncertainty analyses, since the model outputs are not compared to measured values. However, model sensitivities and uncertainties can be analyzed independently of such ground truth measurements. Sensitivity and uncertainty analyses are one valuable way of exploring the potential influence of different environmental settings on model evaluation, without requiring spatially distributed measurements. Since the processes determining the occurrence and characteristics of mountain permafrost are highly complex and nonlinear, a mountain permafrost model is a suitable tool to investigate the variability of model sensitivities and uncertainties in a highly variable environment.

The focus of this study lies on the variability of sensitivities and uncertainties for different topographic and other environmental conditions (Table 1). Here, sensitivity analysis quantifies the variation of the modeled output due to variation in single model parameters, while an uncertainty analysis quantifies the total parametric model output uncertainty due to errors or uncertainties in model parameters. A preliminary parameter calibration (i.e., a minimization of the differences between the model outputs and given values) is performed on selected parameters that influence snow duration most strongly. The object of investigation in this study is

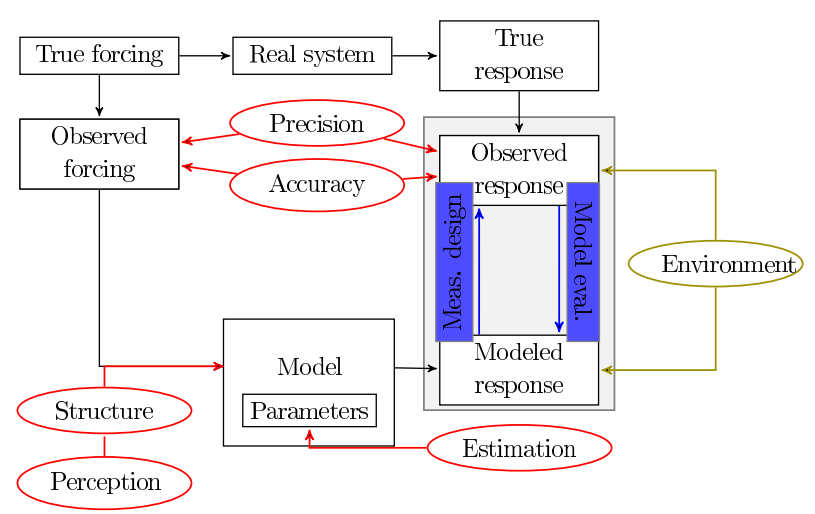

Fig. 1. Model uncertainties and errors has diverse sources (red) such as unknown parameters, errors in input data, numerical errors due to discretization, etc. Uncertainty and sensitivity studies investigate the effect of these possible sources of errors on model outputs (adapted from Gupta et al., 2005). Observed and modeled responses as well as model sensitivities are subject to strong environmental variation.

an energy- and mass-balance model with a primary focus on exploring variables and processes relating to permafrost, i.e., those influencing ground temperatures (GTs). GTs are interesting because they are influenced by highly nonlinear environmental processes such as the energy balance at the Earth's surface, snow cover distribution and snow melting, as well as heat conduction in the ground, which is determined by the thermal properties of the ground constituents and its water content and phase state (e.g., Williams and Smith, 1989). In mountain regions, GTs are strongly coupled to air temperature in summer, and are influenced by solar radiation, snow cover in winter and the ground material (e.g., Haeberli, 1973; Hoelzle, 1996; Keller and Gubler, 1993; Luetschg et al., 2008; Gruber and Hoelzle, 2008). Within a mountainous environment, these variables and processes vary within short distances (e.g., Hoelzle et al., 2003; Gubler et al., 2011), which makes interpolation of model outputs difficult. Similarly, results obtained from model evaluation cannot simply be transferred to other locations. To summarize, the main goals of this study are as follows: (a) to examine the influence of environmental variability on model sensitivity and uncertainty, and discuss the importance of representative model evaluation; (b) to quantify the sensitivity of mean annual ground temperature (MAGT) due to errors in discretization, numerical and model specific parameters and uncertainties in physical parameters; and (c) to discuss the influence of environmental variability on a physically based energy- and mass-balance model. 


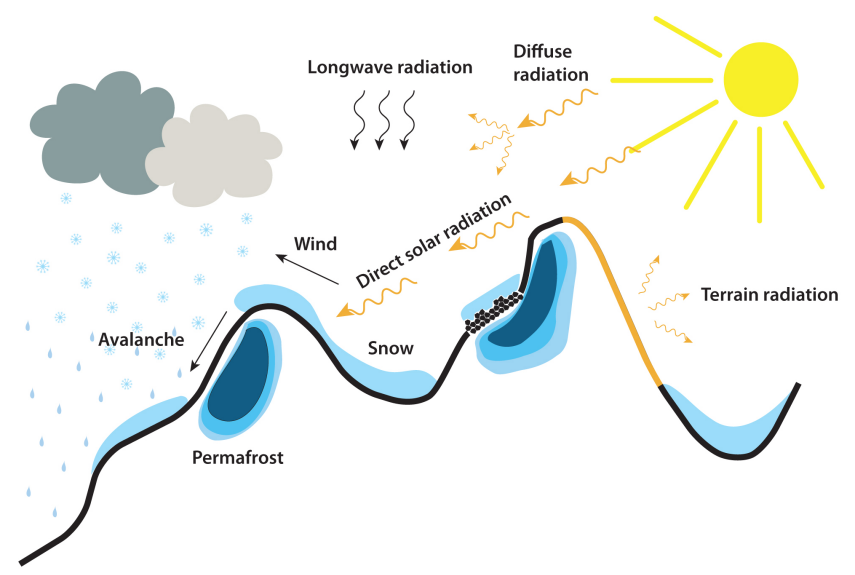

Fig. 2. Processes that influence permafrost are highly variable in mountain areas. The energy balance, shading from surrounding terrain and snow redistribution by wind or avalanches influence permafrost occurrence in high-mountain regions. The scale determines the importance of the influencing processes (Etzelmüller et al., 2001; Hoelzle et al., 2001).

\section{Model and data description}

\subsection{The energy- and mass-balance model GEOtop}

GEOtop is a physically based model originally developed for hydrological research. It couples the ground heat and water budgets, represents the energy exchange with the atmosphere, has a multilayer snow pack and represents the water and energy budget of the snow cover (Bertoldi et al., 2006; Rigon et al., 2006; Endrizzi, 2007; Dall'Amico, 2010). GEOtop simulates the temporal evolution of the snow depth and its effect on ground temperature. It solves the heat conduction equation in one dimension and the Richard's equation for water transport in one or three dimensions describing water infiltration in the ground as well as freezing and thawing processes. GEOtop is therefore a suitable tool to model permafrost relevant variables such as snow and ground temperatures (Fig. 2). It can be applied in high-mountain regions and allows topographic and other environmental variability to be accounted for. This study is performed using the GEOtop version number 1.225-9.

\subsection{Input and validation measurements}

Input data consist of measured air temperature, wind velocity and direction, relative humidity, global radiation and precipitation recorded by the MeteoSwiss meteorological stations. The experiment is run at Piz Corvatsch, Upper Engadine, Switzerland, where a meteorological station of MeteoSwiss is located at $3315 \mathrm{~m}$ a.s.l. A preliminary model analysis is performed at the 40 locations of ground surface temperature measurements around Piz Corvatsch (Gubler et al., 2011). The two main target variables are the mean annual ground surface temperature (MAGST) and the melt-out date of the snow (MD) (Schmid et al., 2012). The study was performed for two years of data, i.e., from summer 2009 to summer 2011.

\subsection{Model parameters}

\subsubsection{Numerical parameters}

In GEOtop, ground discretization is given as the thickness $d z$ of each ground layer. Close to the surface, the ground is resolved in finer detail due to the greater temperature gradients. To reduce the number of degrees of freedom, the thickness of the ground layers is parameterized as an exponential function, describing the ground layer $i$ as

$d z_{i}=d z_{\min } \cdot(1+b)^{i-1}$,

where $d z_{\min }$ is the thickness of the first layer, $b$ is the growth rate and $i$ is the layer index, being one at the ground surface and increasing downwards. In addition, the maximal depth $z_{\max }$ of the modeled ground must be set as a parameter.

Snow resolution is higher close to the snow surface (snowatmosphere interface) and to the ground (snow-ground interface). Snow portions at the top (referred to as the top region) and at the bottom (bottom region) are defined that are discretized with snow layers that never exceed a specified snow water equivalent ( $\mathrm{swe}_{\mathrm{m}}$ ). The top and bottom regions are defined by their maximum snow water equivalent content, respectively given by $n_{\mathrm{t}} \cdot \mathrm{swe}_{\mathrm{m}}$ and $n_{\mathrm{b}} \cdot \mathrm{swe}_{\mathrm{m}}$, where $n_{\mathrm{t}}$ and $n_{\mathrm{b}}$ are integers. However, the portion of the snow pack not included in the top and bottom regions constitutes the middle region, which is discretized with a maximum number $n_{\mathrm{m}}$ of layers with minimum snow water equivalent content equal to $\mathrm{swe}_{\mathrm{m}}$ and no maximum. The layering algorithm prevents the formation of significant snow water equivalent differences across the layers when the value $\mathrm{swe}_{\mathrm{m}}$ is exceeded.

The heat and Richards' equations are solved with the Newton-Raphson method (Kelley, 2003). Significant numerical parameters are the time step $d t$ of numerical integration of the equations and the residual tolerance at which the iterations are terminated. The sensitivity of the GEOtop model to both these parameters are also quantified in this study. The time step has been made to vary in the range from $7.5 \mathrm{~min}$ to $4 \mathrm{~h}$. The higher the time step and residual tolerance are, the longer the computing time is. The optimal parameters for the simulation are the highest time step, and residual tolerance for which a decrement of their value does not result in a significant numerical solution difference.

\subsubsection{Model-specific parameters}

An initial condition of the state variables, namely temperature and total (= ice + liquid water) soil moisture initial profiles, must be assigned to run the model. Since there is always a certain degree of arbitrariness in this, the simulations 
are then run for a long time so that they lose memory of the initial values and will assume values in equilibrium with the meteorological forcings and the ground properties. The ground column in the model is $10 \mathrm{~m}$ deep, and is initialized by repeatedly modeling GT down to $1 \mathrm{~m}(40 \mathrm{yr})$, then using the modeled GTs as initial condition to repeatedly simulate GT down to $5 \mathrm{~m}$ ( $40 \mathrm{yr}$ ) and finally simulating GTs down to $10 \mathrm{~m}$ depth. Preliminary analyses have shown that this procedure produces stable initial conditions of the ground. To test possibly different responses that may take place if the initial condition is given by unfrozen and frozen ground, a sensitivity study with negative $\left(-1{ }^{\circ} \mathrm{C}\right)$ and positive $\left(+1{ }^{\circ} \mathrm{C}\right)$ initial ground temperatures is performed. The initial total soil moisture profile is obtained from the retention curve after assigning a hydrostatic water pressure profile, and then the total soil moisture in ice and liquid water is split according to ground temperature and the freezing soil characteristic curve (e.g., Dall'Amico, 2010).

Although this study deals with one-dimensional simulations, it is possible to represent lateral water drainage between the surface and a depth referred to as $z_{f}$, while below this depth the ground can be filled with water until it is saturated. Depending on the interests of the modeler, the water balance can be turned off if no information on the ground hydraulic properties are available in order to save computation time or to study the influence of water balance on model outputs.

The longwave downward radiation (LDR) parameterizations implemented in GEOtop are based on the StefanBoltzmann law:

$\mathrm{LWR}_{\mathrm{in}}=\epsilon_{\mathrm{atm}} \cdot \sigma_{\mathrm{SB}} \cdot T_{\mathrm{atm}}^{4}$,

where $\sigma_{\mathrm{SB}}=5.67 \times 10^{-8} \mathrm{~W} \mathrm{~m}^{-2} \mathrm{~K}^{-4}$ denotes the StefanBoltzmann constant, $\epsilon_{\mathrm{atm}}$ the bulk emissivity and $T_{\text {atm }}$ the effective temperature of the overlying atmosphere. In practice, $T_{\mathrm{atm}}$ is replaced by the temperature at screen-level height temperature $T$, and the atmospheric emissivity is parameterized as a function of air temperature and/or vapor pressure. Diverse LDR parameterizations can be found in the literature (Brutsaert, 1975; Idso, 1981; Konzelmann et al., 1994; Prata, 1996, among others). GEOtop includes a switch to select one out of nine parameterizations. Gubler et al. (2012) calibrated these parameterizations to measured longwave radiation in Switzerland. The sensitivity on the different LDR parameterizations, as well as on the calibrated Konzelmann et al. (1994) parameterization, is tested.

The turbulent fluxes of sensible and latent heat are calculated using the Monin-Obukhov similarity theory (Obukhov, 1946; Monin and Obukhov, 1954), which represents the effect of buoyancy with corrections to the logarithm profile of wind speed, valid only in a neutral atmosphere. However, the theory only determines the functional dependence of the corrections. Their mathematical formulation has to be found empirically. For this reason, in the present study the possibility to represent the turbulent fluxes assuming a neutral atmosphere is also considered. This becomes very important when the atmosphere is stable, because in this case the Monin-Obukhov corrections may improperly suppress turbulence and, as a result, the surface may be decoupled from the atmosphere, causing significant errors. If the wind speed is very small, such decoupling may also occur. Therefore, a minimum wind speed $\left(V_{\min }\right)$ has been added as a parameter. A minimum relative humidity $\left(\mathrm{RH}_{\min }\right)$ has also been added to prevent unrealistic turbulent fluxes. Temperature thresholds for rain $T_{\mathrm{r}, 0}$ and snow $T_{\mathrm{s}, 0}$ determine the temperature above which all precipitation is rain and below which all precipitation is snow. Between the two thresholds, the amount of precipitation that is rain or snow is interpolated linearly. They are set from 0 to $4{ }^{\circ} \mathrm{C}$ for rain, and -3 to $0^{\circ} \mathrm{C}$ for snow (Kienzle, 2008).

\subsubsection{Physical parameters}

The parameters considered for ground are its aerodynamical roughness, ground albedo and emissivity, as well as its hydraulic properties presented in Sect. 2.4.2. The ground roughness influences the turbulent fluxes, and ranges from few millimeters up to half a meter or more depending on terrain obstacles (Wieringa, 1993). The albedo of a dry ground surface $\alpha_{\mathrm{g}, \text { dry }}$ is assumed to range from 0.1 to 0.4 , values that are typically found in the literature (e.g., Ångström, 1925; Tetzlaff, 1983; Ineichen et al., 1990; Scharmer and Greif, 2000; Markvart and Castañer, 2003; Polo et al., 2012), with an average of 0.2. The reflection of wet ground $\alpha_{\mathrm{g} \text {, wet }}$ is smaller than for dry ground (Ångström, 1925), modeled as

$\alpha_{\mathrm{g}, \mathrm{wet}}=\alpha_{\mathrm{g}, \mathrm{dry}} \cdot f_{\alpha_{\mathrm{g}, \mathrm{wet}}}$,

where $0.4 \leq f_{\alpha_{\mathrm{g}, w e t}} \leq 1$. Emissivity of the different ground types is assumed between 0.8 and 0.99 with an average of 0.96 (e.g., Sutherland, 1986; Ogawa and Schmugge, 2004; Jin and Shunlin, 2006). The heat flux at the bottom of the ground profile determines the lower boundary condition of the heat conduction. The deep ground heat flux is $0.07 \mathrm{~W} \mathrm{~m}^{-2}$ (Medici and Rybach, 1995). Due to geometrical effects in high-mountain regions, the density of the ground heat flux in complex topographies varies (Kohl, 1999; Nötzli et al., 2007), and is hence assumed to have an average value of 0.05 .

Diverse parameters concerning snow such as the snow reflectance, its emissivity, roughness, viscosity and the snow compaction rate can be set in GEOtop, determining the outgoing longwave radiation, the turbulent fluxes and the snow densification, They influence snow melt and the duration of the snow cover in spring. For shallow snow packs, snow albedo decreases since a significant portion of incoming shortwave radiation is actually absorbed by the ground surface (Tarboton and Luce, 1996). In GEOtop, this is represented by the albedo extinction parameter $c_{\alpha}$. If the snow 
Table 1. Environmental attributes determining the locations for which the sensitivity and uncertainty analyses are performed. The sky view factor (SVF) is a function of slope. For each combination of attributes, a separate sensitivity and uncertainty analysis is performed, resulting in a total of 200 simulation locations per ground type. In total, 1200 sensitivity and uncertainty analyses were performed.

\begin{tabular}{llrrr}
\hline Attribute & Unit & Min. & Max. & Step \\
\hline Elevation & $\mathrm{m}$ & 500 & 4000 & 500 \\
Aspect & deg. & 0 & 360 & 45 \\
Slope & deg. & 0 & 30 & 10 \\
SVF & & 0.93 & 1 & \\
Ground & & 1 & 6 & e.g., Table 2 \\
\hline
\end{tabular}

height $z$ is smaller than $c_{\alpha}$, ground and snow albedo are linearly interpolated. Snow emissivity ranges from 0.94 to 0.99 , with an baseline value of 0.98 (e.g., Dozier and Warren, 1982; Zhang, 2005; Hori et al., 2006). The albedo of fresh snow for visible light is between 0.8 and 0.96 (e.g., Markvart and Castañer, 2003). The uncertainties in the atmospheric parameters that determine the attenuation of solar radiation are according to Gubler et al. (2012).

\subsubsection{Input measurements and extrapolation}

Air temperature is extrapolated at different elevations using a lapse rate. Analogous to air temperature, dew point temperature and precipitation are also distributed at different elevations using an elevation-related lapse rate. Precipitation measurements can have a negative bias due to wetting loss or wind-induced undercatch (Legates and DeLiberty, 1993; Goodison et al., 1998), for example. To deal with this systematic measurement error that has great effect on snow accumulation and soil moisture, GEOtop considers a precipitation correction factor. Hence, all precipitation measurements used as input to the model are multiplied with the correction factor. The value of the correction factor is assigned before running the model, and may be used for tuning.

The height of the sensor at which a temperature or wind speed is measured influences the calculation of the turbulent fluxes. While the exact height of the meteorological station can be measured precisely, the topography of the station in mountain regions may influence the equivalent height with respect to an infinite planar surface (Fig. 3). As a consequence, its determination is partly arbitrary. In this study, the height is varied between 0.5 and $16 \mathrm{~m}$.

\subsection{Experimental setting}

The sensitivity study is performed for six different ground types (Sect. 2.4.2), which are varied within a topographical setting typical for mountain areas (Table 1). GEOtop is run for all combinations of ground types and topographical

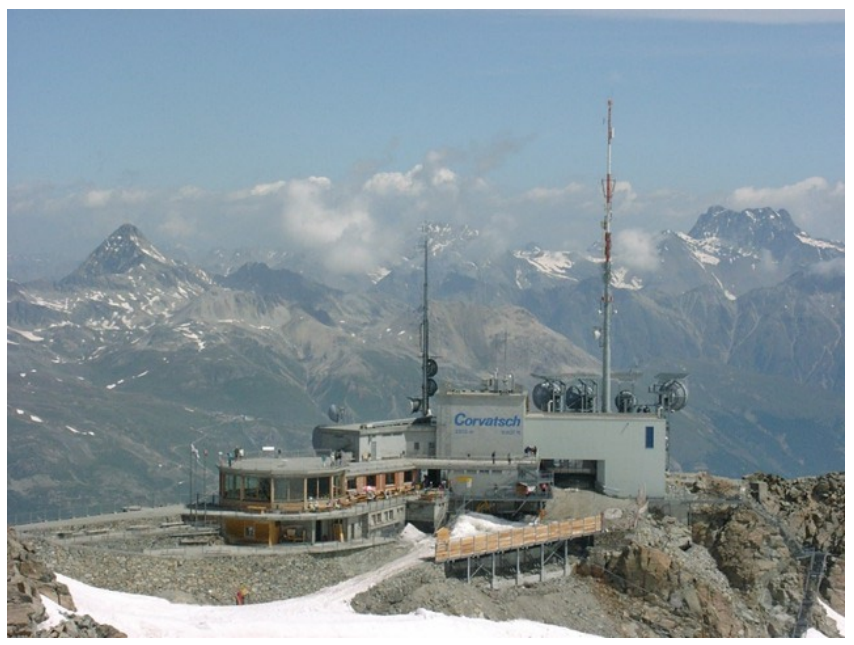

Fig. 3. The height of the meteorological station at Piz Corvatsch is assumed uncertain, ranging from 0.5 to $16 \mathrm{~m}$. Within mountain topography, the actual height in relation with the surroundings at the top of a mountain cannot be accurately determined. In the figure, the meteorological station is just above the "tsch" of "Corvatsch".

attributes that are assumed important when modeling mountain permafrost.

\subsubsection{Topography}

The modeling study is performed within an artificial set of topographic attributes to evaluate the sensitivities of GEOtop for diverse topographical situations (Table 1). We model elevations in steps of $500 \mathrm{~m}$ from 500 to $4000 \mathrm{~m}$ a.s.l. Slope varies from $0^{\circ}$ to $30^{\circ}$ in steps of $10^{\circ}$, and aspect is varied in steps of $45^{\circ}$, thereby covering the most important exposure to the sun. In total, this topography sampling results in a total of 1200 simulation points. All locations where snow did not melt in summer were excluded from the analysis.

\subsubsection{Ground types}

Different ground types and ground surface covers influence the ground thermal regime substantially. Liquid water influences the thermal conductivity of the ground as well as the latent heat transfer during freezing and thawing of a specific ground layer (Williams and Smith, 1989). The study was performed for six different ground types: clay, sand, silt, peat, gravel and rock. For each of these ground types, typical values for the residual water content $\theta_{\mathrm{r}}$, the saturated water content $\theta_{\mathrm{s}}$, the parameters $n_{\mathrm{vG}}$ and $\alpha_{\mathrm{VG}}$ determining the shape of the water retention curve parameterized according to van Genuchten (1980) and the saturated hydraulic conductivity $K_{\mathrm{h}}$ are determined (Table 2). The lateral hydraulic conductivity is assumed to be the same as the normal hydraulic conductivity. The thermal conductivity $K_{T}$ is set to $2.5 \mathrm{~W} \mathrm{~m}^{-1} \mathrm{~K}^{-1}$ and the thermal capacity $C$ of the mineral particles to $2.25 \times 10^{6} \mathrm{~J} \mathrm{~m}^{-3} \mathrm{~K}^{-1}$ for the 
Table 2. Parameters of the different ground types. In the sensitivity analysis, the hydraulic parameters are assumed to change by $\pm 20 \%$ for $\theta_{\text {sat }}, \pm 10 \%$ for $\theta_{\text {res }}, \pm 50 \%$ for $n_{\mathrm{vG}}$ and $\pm 25 \%$ for $\alpha_{\mathrm{vG}}$, and goes from 0.01 to 100 times the original value for $K_{\mathrm{h}}$. The thermal conductivity changes by $50 \%$ and the heat capacity changes by $20 \%$ as shown in Table 3 ). The values are modified by the respective factors presented in Table 3 .

\begin{tabular}{lllrrrrrr}
\hline Parameter & Symbol & Unit & Clay & Silt & Sand & Peat & Gravel & Rock \\
\hline Residual water content & $\theta_{\mathrm{r}}$ & & 0.072 & 0.057 & 0.055 & 0.2 & 0.055 & 0.002 \\
Saturated water content & $\theta_{\mathrm{S}}$ & & 0.475 & 0.487 & 0.374 & 0.85 & 0.374 & 0.05 \\
van Genuchten $\alpha$ & $\alpha_{\mathrm{VG}}$ & $\mathrm{mm}^{-1}$ & 0.001 & 0.001 & 0.003 & 0.03 & 0.1 & 0.001 \\
van Genuchten $n$ & $n_{\mathrm{vG}}$ & & 1.4 & 1.6 & 3.2 & 1.8 & 2 & 1.2 \\
Hydraulic conductivity & $K_{\mathrm{h}}$ & $\mathrm{mm} \mathrm{s}^{-1}$ & 0.0019 & 0.0051 & 0.0825 & 0.3 & 10 & 0.000001 \\
Thermal conductivity & $K_{T}$ & $\mathrm{~W} \mathrm{~m}^{-1} \mathrm{~K}^{-1}$ & 2.5 & - & - & - & - & - \\
Thermal capacity & $C$ & $\mathrm{~J} \mathrm{~m}^{-3} \mathrm{~K}^{-1}$ & $2.25 \times 10^{6}$ & - & - & - & - & - \\
\hline
\end{tabular}

mineral particles (e.g., Cermák and Rybach, 1982; Wegmann et al., 1998; S̆afanda, 1999). Ground is defined here as the volume below Earth's surface for which temperature is studied. Coarse blocks such as typically found on rock glaciers are important to model permafrost in the Alps. In this setting, we parameterize them with the hydrologic conductivity of gravel and a high porosity. This allows for a free drainage of the pore space, and the corresponding air content is accounted for in the calculation of ground thermal conductivity that constitutes one element of the importance of coarse blocks for permafrost (Gruber and Hoelzle, 2008). The advection of air in blocky surfaces, which is a complex problem that we are not yet in the position to address, is not included in the model.

The parameter values for silt, sand and clay are taken from Twarakavi et al. (2010, Table 2). For peat, the parameter values come from Carey et al. (2007) and Quinton et al. (2008). Residual and saturated water content for gravel is assumed to be similar to sand. The van Genuchten parameters and the hydraulic conductivity for gravel are approximated from Maier et al. (2009). For rock, they are assumed to be the same as for clay, and the hydraulic conductivity, and $\theta_{\mathrm{r}}$ and $\theta_{\mathrm{s}}$ are assumed to be very small. Measurements of the van Genuchten parameters for rock were not found in the literature.

\subsection{Target variable}

Ground temperatures are linearly interpolated between the simulation nodes that represent layers in the numerical scheme. Thereby, the modeled MAGT are compared at the same depths. The annual mean, minimum and maximum values at $10 \mathrm{~cm}, 1 \mathrm{~m}, 5 \mathrm{~m}$ and $10 \mathrm{~m}$ depth are calculated.

\section{Experiments}

This sensitivity and uncertainty study was performed based on the energy- and mass-balance model GEOtop (Rigon et al., 2006) (Sect. 2.1). A local sensitivity analysis (Sect. 4.2) on individual parameters was performed with a special focus on variations within topographically variable terrain
(Sect. 2.4.1). Then, a subset of sensitive physical parameters was selected to quantify the total parametric output uncertainty of GEOtop (Sect. 3.3).

\subsection{Preliminary analysis}

The parameters that predominantly influence the duration of snow cover were calibrated in a preliminary analysis, since snow exerts great influence on ground temperatures through insulation (Zhang, 2005; Goodrich, 1982). The error of simulated melt-out day (MD) is compared to MD observed at 39 locations around Piz Corvatsch (Gubler et al., 2011; Schmid et al., 2012). MD is simulated for diverse parameter sets obtained by globally varying the most important parameters that influence MD. The simulations are calibrated with the observations to obtain parameter values that minimize the difference between model outputs and observations.

\subsection{Sensitivity analysis}

A model can be regarded as a black box represented by a function $f\left(x_{1}, x_{2}, \ldots, x_{n}\right)=\left(y_{1}, y_{2}, \ldots, y_{\mathrm{m}}\right)$, where $\left(x_{1}, x_{2}, \ldots, x_{n}\right)$ are the model parameters and $\left(y_{1}, y_{2}, \ldots, y_{\mathrm{m}}\right)$ are the model outputs. To evaluate GEOtop, a sensitivity analysis on 52 individual parameters is performed to (a) quantify the influence of each parameter on the output variables of interest and (b) to determine the most important physical parameters for the subsequent uncertainty analysis. The sensitivity of a parameter $x_{j}$ is determined by keeping all parameters $x_{i}, i \neq j$ fixed at their baseline value $X_{j_{0}}=\left(x_{10}, x_{20}, \ldots, x_{(j-1)_{0}}, x_{(j+1)_{0}}, \ldots, x_{n 0}\right)$, and varying $x_{j}$ within values that are physically plausible. The ranges of the parameters are determined based on review of the literature and/or expert opinion. However, it must be kept in mind that, even though intended to be as objective as possible, the selection of a parameter range has a subjective part that influences the results and conclusions that are obtained from the analysis. The variation of the model outputs $y_{k}, k=1, \ldots, m$ is evaluated to quantify the local sensitivities $s_{j, k}$ that are defined here as the range of the $95 \%$ of the simulated outputs. 
Local sensitivities are obtained when each parameter is varied separately and all others are kept fixed. This procedure contrasts to global sensitivities, where all parameters are changed simultaneously (e.g., Saltelli et al., 2004, 2008).

The parameters are categorized into (a) very sensitive parameters, (b) sensitive parameters and (c) nonsensitive parameters. Category (a) includes all parameters that are tuned in a preliminary analysis (Sect. 3.1). The second category includes all parameters having non-negligible influence to the model outputs. All physical parameters changing MAGT by at least $0.5^{\circ} \mathrm{C}$ in the sensitivity analysis are included in the uncertainty analysis.

\subsection{Uncertainty analysis}

A prior distribution is assigned to each of the selected physical parameters. If a parameter has only positive values, it is assumed to be log-normally distributed, otherwise it follows a normal distribution. All parameters are assumed independent from each other. Since the study setting is synthetic, spatial autocorrelation of the parameters are not taken into account. The location parameter is the average of the parameter values determined for the local sensitivity analysis (e.g., Table 3), and the standard deviation is chosen such that the range encloses $95 \%$ of the values for a normally distributed parameter. If a parameter is log-normally distributed (e.g., $x \sim \mathcal{L}\left(\mu, \sigma^{2}\right)$ ), the expected value $E[X]$ is the baseline value , and the variance $\operatorname{Var}[X]$ is chosen appropriately representing the variability of the parameter. The statistical parameters of the log-normal distribution are

$$
\begin{aligned}
& \sigma=\log \left(\frac{\operatorname{Var}[X]}{E[X]}+1\right), \\
& \mu=\log (E[X])-\frac{\sigma^{2}}{2} .
\end{aligned}
$$

Each parameter is sampled according to its prior distribution, and a GEOtop simulation is performed for each parameter set. In total, 1500 model simulations were performed to ensure convergence of the output probability distribution (Fig. 10). The results are depicted as relative frequency histograms to evaluate the total model output uncertainty, and are quantified as the length of the $95 \%$ uncertainty interval of the simulations.

\subsection{Model simulations}

The sensitivity and uncertainty analyses were performed systematically for different ground types within a setting representing the topographic variability encountered in mountain regions (Sect. 2.4). In total, 1200 locations were simulated. The sensitivity analysis required 256 simulations, and the uncertainty analysis a total of 1500 simulations at each location. In total, more than 2 million GEOtop simulations were performed. The simulations are visually analyzed using small-multiple plots (Tufte, 1983, 1990) (e.g., Fig. 7), and are

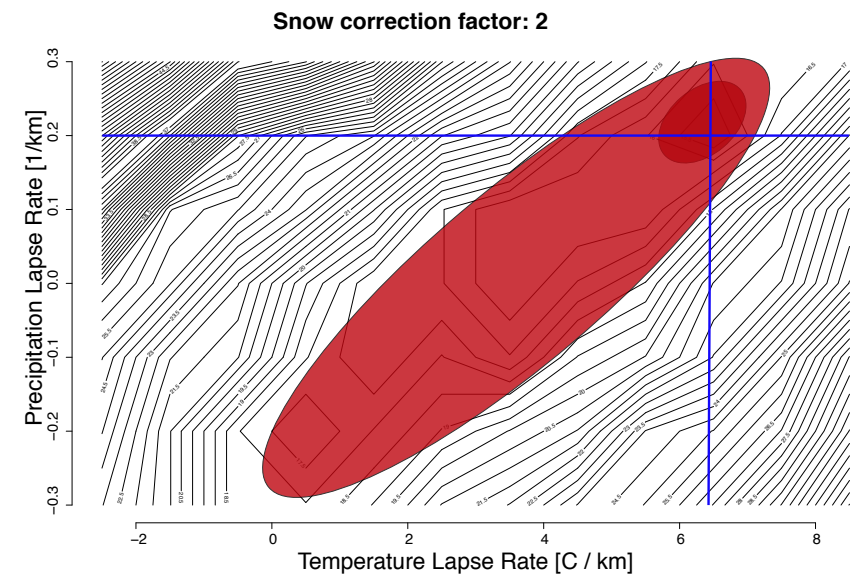

Fig. 4. Contour plot of the RMSD for simulated compared to observed MD around Piz Corvatsch, Switzerland (Gubler et al., 2011; Schmid et al., 2012). The smallest RMSDs are obtained for a a temperature lapse rate $6.5^{\circ} \mathrm{C} \mathrm{km}^{-1}$, a snow correction factor of 2 and a precipitation lapse rate of $0.2 \mathrm{~km}^{-1}$ (indicated by the blue lines).

summarizedat least one ground in box plots for the different locations and ground types.

\section{Results}

\subsection{Preliminary analysis}

A preliminary analysis was conducted to extract reasonable values of the parameters that most considerably influence snow duration (i.e., the melt-out day (MD)). The temperature and precipitation lapse rates and the snow correction factor were calibrated using MD derived from ground surface temperature measurements around Piz Corvatsch (Gubler et al., 2011; Schmid et al., 2012). Due to a compensating effect, different parameter combinations lead to similar results (Beven and Freer, 2000) (Fig. 4). We chose to set the temperature lapse rate to its most commonly used value of $-6.5^{\circ} \mathrm{C} \mathrm{km}^{-1}$, resulting in an optimal precipitation lapse rate of $0.2 \mathrm{~km}^{-1}$ and a snow correction factor of 2 (Fig. 4). That results in an average MD error of zero days with a root-mean-squared error of less than 20 days for both study years 2010 and 2011. Precipitation lapse rate in mountain areas are normally negative accounting for greater snow accumulation in high-elevation areas (e.g., Barringer, 1989). Downward transportation of snow by avalanches or wind in the study area, processes that are not represented in GEOtop, may be the reason for the positive precipitation lapse rate. The sensitivity to different LDR parameterizations was reduced using the calibration performed by Gubler et al. (2012). 
Table 3. Parameters selected for the sensitivity study. The minimum and the maximum indicate the range from which the parameters are sampled, and base indicates the standard choice used in, e.g., local sensitivity studies. The columns below "Uncertainty" indicate the properties of the prior distributions of the parameters considered in the uncertainty analysis. The values of the two LDR parameters (Konzelmann et al., 1994) change between 0.484 and 0.43 , and 5.7 and 8 (Gubler et al., 2012).

\begin{tabular}{|c|c|c|c|c|c|c|c|c|}
\hline \multirow[t]{2}{*}{ Parameter } & \multirow[t]{2}{*}{ Symbol } & \multirow[t]{2}{*}{ Unit } & \multirow[t]{2}{*}{ Base } & \multicolumn{2}{|c|}{ Sensitivity } & \multicolumn{3}{|c|}{ Uncertainty } \\
\hline & & & & Min. & Max. & Distr. & $\mathrm{Par}_{1}$ & $\mathrm{Par}_{2}$ \\
\hline \multicolumn{9}{|l|}{ Numerical parameter } \\
\hline Thickness of first ground layer & $d z_{\min }$ & $\mathrm{mm}$ & 20 & 5 & 640 & & & \\
\hline Growth rate ground depth & $b$ & & 0.5 & 0 & 1 & & & \\
\hline Maximal ground depth & $z_{\max }$ & $\mathrm{m}$ & 10 & 1.25 & 20 & & & \\
\hline Number of top snow layers & $n_{\mathrm{t}}$ & & 4 & 1 & 10 & & & \\
\hline Number of bottom snow layers & $n_{\mathrm{b}}$ & & 2 & 1 & 10 & & & \\
\hline Number of snow layers in middle & $n_{\mathrm{m}}$ & & 4 & 1 & 64 & & & \\
\hline Typical SWE & $\mathrm{swe}_{\mathrm{m}}$ & $\mathrm{mm}$ & 10 & 1.25 & 40 & & & \\
\hline Time discretization & $d t$ & $\mathrm{~h}$ & 1 & 0.125 & 4 & & & \\
\hline Richard's tolerance & tol $_{\mathrm{r}}$ & $\mathrm{mm}$ & $10^{-4}$ & $10^{-8}$ & $10^{-4}$ & & & \\
\hline Heat equation tolerance & tol $_{h}$ & $\mathrm{Jm}^{-2}$ & $10^{-4}$ & $10^{-8}$ & $10^{-4}$ & & & \\
\hline \multicolumn{9}{|l|}{ Model parameter } \\
\hline Minimal wind velocity & $V_{\min }$ & $\mathrm{ms}^{-1}$ & 0.5 & 0.01 & 1.28 & & & \\
\hline Minimal relative humidity & $\mathrm{RH}_{\min }$ & $\%$ & 10 & 1 & 10 & & & \\
\hline LDR calibration & $\mathrm{LDR}_{\text {in }, \mathrm{K}}$ & & & & & & & \\
\hline Monin-Obukhov param. & $\mathrm{MO}$ & & 1 & 1 & 4 & & & \\
\hline Water balance & WB & & 1 & 0 & 1 & & & \\
\hline \multicolumn{9}{|l|}{ Physical parameter } \\
\hline Initial ground temperature & $T_{\mathrm{i}}$ & ${ }^{\circ} \mathrm{C}$ & 1 & -1 & 1 & & & \\
\hline Depth above which water drains & $z_{f}$ & $\mathrm{~m}$ & 10 & 0.01 & 10 & Unif & 0 & 10 \\
\hline Extinction parameter snow albedo & $c_{\alpha}$ & $\mathrm{mm}$ & 10 & 0 & 200 & $\log -\mathrm{N}$ & 1.71 & 1.09 \\
\hline Ground roughness & $r_{\mathrm{g}}$ & $\mathrm{mm}$ & 10 & 0.01 & 100 & Log-N & 1.96 & 0.83 \\
\hline Dry ground albedo & $\alpha_{\mathrm{g}, \text { dry }}$ & & 0.2 & 0.1 & 0.4 & Norm & 0.25 & 0.05 \\
\hline Divisor wet ground albedo & $f_{\alpha_{\mathrm{g}, \text { wet }}}$ & & 1 & 1 & 2.5 & Norm & 1.75 & 0.25 \\
\hline Ground emissivity & $\epsilon_{\mathrm{g}}$ & & 0.96 & 0.81 & 0.99 & Norm & 0.93 & 0.02 \\
\hline Ground heat flux & $Q_{\mathrm{g}}$ & $\mathrm{Wm}^{-2}$ & 0.05 & -0.1 & 0.1 & & & \\
\hline Snow roughness & $r_{\mathrm{s}}$ & $\mathrm{mm}$ & 0.1 & 0.01 & 10 & $\log -\mathrm{N}$ & -2.64 & 0.83 \\
\hline Fresh snow albedo (vis) & $\alpha_{\mathrm{s}, \mathrm{vis}}$ & & 0.96 & 0.8 & 0.96 & Norm & 0.93 & 0.02 \\
\hline Fresh snow albedo (nir) & $\alpha_{\mathrm{s}, \mathrm{NIR}}$ & & 0.65 & 0.6 & 0.7 & Norm & 0.65 & 0.02 \\
\hline Snow emissivity & $\epsilon_{\mathrm{S}}$ & & 0.98 & 0.96 & 0.99 & & & \\
\hline Snow viscosity & $v_{\mathrm{S}}$ & $\mathrm{Nsm}^{-2}$ & $10^{6}$ & $10^{6}$ & $8 \times 10^{6}$ & Norm & $4 \times 10^{6}$ & $2 \times 10^{6}$ \\
\hline Ground-snow roughness threshold & $c_{\mathrm{S}, \mathrm{r}}$ & $\mathrm{mm}$ & 1 & 0.5 & 1 & & & \\
\hline Irreducible water saturation snow & $s_{\mathrm{W}, \mathrm{irr}}$ & & 0.02 & 0.005 & 0.08 & Log-N & -4.02 & 0.47 \\
\hline Snow density cutoff & $d_{\mathrm{s}, \mathrm{cut}}$ & $\mathrm{kg} \mathrm{m}^{-3}$ & 100 & 75 & 175 & Log-N & 4.58 & 0.2 \\
\hline Dry snow deformation rate & $d f_{\mathrm{s}, \text { dry }}$ & $\%$ & 1 & 0.75 & 1.25 & & & \\
\hline Wet snow deformation rate & $d f_{\mathrm{s}, \text { wet }}$ & $\%$ & 1.5 & 1.25 & 2.5 & & & \\
\hline Temperature threshold rain & $T_{\mathrm{r}, 0}$ & ${ }^{\circ} \mathrm{C}$ & 3 & 0 & 4 & Norm & 2 & 0.5 \\
\hline Temperature threshold snow & $T_{\mathrm{S}, 0}$ & ${ }^{\circ} \mathrm{C}$ & -1 & -3 & 0 & Norm & -1.75 & 0.5 \\
\hline Ozone & $\mathrm{O}_{3}$ & $\mathrm{~mm}$ & 0.314 & 0.238 & 0.39 & & & \\
\hline Ångström $\alpha$ & $\alpha_{\AA}$ & & 1.38 & 0.46 & 2.30 & & & \\
\hline Ångström $\beta$ & $\beta_{\AA}^{A}$ & & 0.039 & 0.010 & 0.139 & $\log -\mathrm{N}$ & -3.73 & 0.99 \\
\hline Albedo to determine SDR & $\alpha_{c}^{A}$ & & 0 & 0 & 1 & & & \\
\hline Residual water content $(F)$ & $f_{\theta_{\mathrm{res}}}$ & & 1 & 0.8 & 1.2 & & & \\
\hline Saturated water content $(F)$ & $f_{\theta_{\text {sat }}}$ & & 1 & 0.9 & 1.1 & Norm & 1 & 0.05 \\
\hline van Genuchten parameter $\alpha(F)$ & $f_{\alpha_{\mathrm{vG}}}$ & & 1 & 0.75 & 1.25 & & & \\
\hline van Genuchten parameter $n(F)$ & $f_{n_{\mathrm{VG}}}$ & & 1 & 0.5 & 1.5 & Norm & 1 & 0.25 \\
\hline Hydraulic conductivity $(F)$ & $f_{K_{\mathrm{h}}}$ & & 1 & 0.01 & 100 & Norm & 0 & 1 \\
\hline Thermal capacity $(F)$ & $f_{\mathrm{C}}$ & & 1 & 0.8 & 1.2 & & & \\
\hline Thermal conductivity $(F)$ & $f_{K_{T}}$ & & 1 & 0.5 & 1.5 & Norm & 1 & 0.25 \\
\hline \multicolumn{9}{|l|}{ Input } \\
\hline Temperature lapse rate & $\Gamma_{T}$ & ${ }^{\circ} \mathrm{Ckm}^{-1}$ & 6.5 & 5.5 & 7.5 & & & \\
\hline Dew point temperature lapse rate & $\Gamma_{D T}$ & ${ }^{\circ} \mathrm{Ckm}^{-1}$ & 2.5 & 1.5 & 3.5 & & & \\
\hline Precipitation lapse rate & $\Gamma_{\mathrm{P}}$ & $\mathrm{km}^{-1}$ & 0.2 & -0.1 & 0.3 & & & \\
\hline Correction factor for precip. & $c_{\mathrm{P}}$ & & 2 & 1.6 & 2.4 & & & \\
\hline Sensor height wind velocity & $h_{\mathrm{W}}$ & $\mathrm{m}$ & 2 & 0.5 & 16 & $\log -\mathrm{N}$ & 0.66 & 0.25 \\
\hline Sensor height temperature & $h_{T}$ & $\mathrm{~m}$ & 2 & 0.5 & 16 & Log-N & 0.66 & 0.25 \\
\hline
\end{tabular}




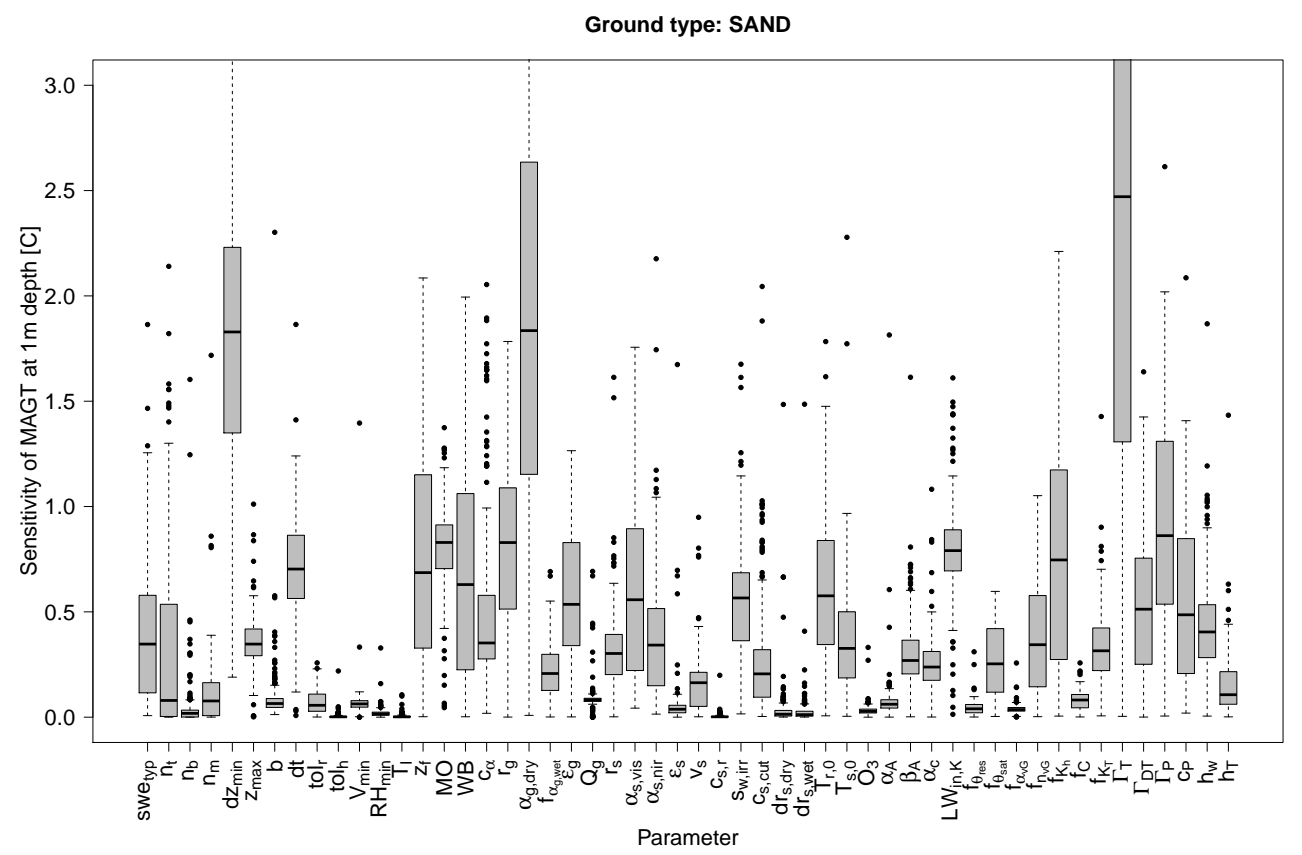

Fig. 5. Sensitivities of the target variable MAGT at $1 \mathrm{~m}$ depth $\left[{ }^{\circ} \mathrm{C}\right]$ for sandy ground. The sensitivities of the topographic locations are summarized as box plots. The greater the spread of the box, the higher the variability of the sensitivity within the topographic setting. The range of the box plots is equivalent to the "potential of being mislead" by the results of a sensitivity analysis performed at one single location. See Table 3 for an explanation of parameter names.

\subsection{Summarized sensitivities}

\subsubsection{Topographic setting}

MAGT sensitivities at different depths correlate strongly, and hence all the presented results concern MAGT modeled at $1 \mathrm{~m}$ depth. The sensitivities to the individual parameters vary strongly for different topographic factors (Fig. 5). Differences in the temperature lapse rate $\Gamma_{T}$ of $2{ }^{\circ} \mathrm{C} \mathrm{km}^{-1}$ (5.5 to $7.5^{\circ} \mathrm{Ckm}^{-1}$ ) result in maximal ground temperature differences of up to $5^{\circ} \mathrm{C}$ for an elevation distance of $1000 \mathrm{~m}$ between the modeled location and the meteorological station. The minimal sensitivity to $\Gamma_{T}$ is less than $0.2{ }^{\circ} \mathrm{C}$ at locations of similar elevation as the meteorological station. The sensitivity to the temperature lapse rate increases linearly with the distance to the meteorological station.

The sensitivity to the dry ground albedo increases at southexposed slopes that receive more solar radiation than adjacent slopes exposed to the north (Fig. 7). Further, lowelevation sites are more sensitive to the dry ground albedo since the snow duration is shorter there. The opposite is the case for the snow albedo, which has an enhanced sensitivity at high elevations. The sensitivity to ground roughness, the height at which wind velocity is measured, and the dew point temperature lapse rate increases for decreasing elevations. This indicates the increased importance of the turbulent fluxes in the energy balance for locations of increasing air temperatures and decreasing solar radiation.

\subsubsection{Discretization errors}

\section{Ground}

The sensitivity to the thickness of the first layer $d z_{\min }$ increases linearly with increasing $d z_{\min }$ for ground types sand, peat and gravel (Fig. 6). For clay, silt and rock, the sensitivity to $d z_{\min }$ increases only for $d z_{\min } \geq 40 \mathrm{~mm}$, while below that threshold it is zero. The sensitivity to $d z_{\min }$ is smaller for MAGT close to $0^{\circ} \mathrm{C}$, i.e., at high elevations. The highest sensitivities to $d z_{\min }$ are obtained for peat, gravel and rock (Fig. 9). For rock, this results in changes of almost $4{ }^{\circ} \mathrm{C}$. Up to $20-40 \mathrm{~mm}$, the median sensitivity to $d z_{\min }$ is relatively small (Fig. 8, bottom right figure) for all environmental conditions studied here, and it increases linearly for greater values. The maximal ground thickness $z_{\max }$ is not sensitive (except for few locations in rock). The ground layer thickness parameter $b$ is insensitive to all ground types and topographic settings.

\section{Time}

The time step for which the numerical equations are solved results in maximal MAGT differences of 0.9 to $1.3^{\circ} \mathrm{C}$ changes. The minimal sensitivity to the time step is around $0.2{ }^{\circ} \mathrm{C}$. The sensitivity to the time step is negligible up to $15 \mathrm{~min}$, and then increases linearly (Fig. 8, top left figure). We conclude that, if computation time is no issue, the heat 
GRAVEL
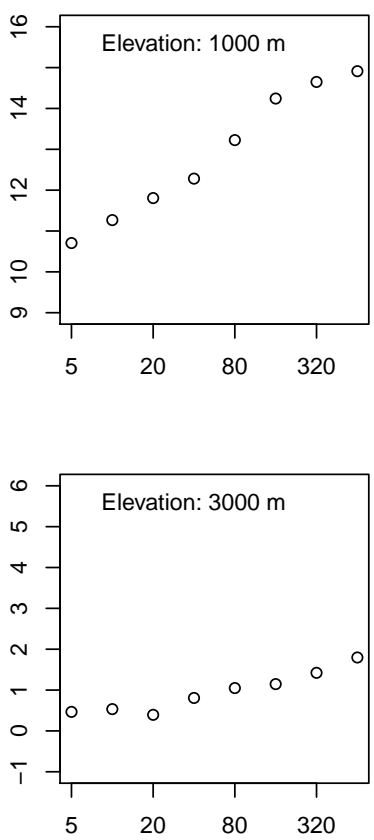

CLAY
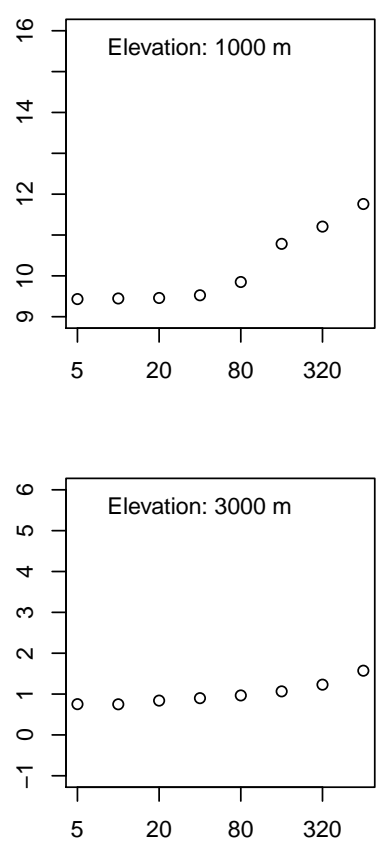

Fig. 6. Sensitivities of MAGT modeled at $10 \mathrm{~cm}$ depth to the thickness of the first ground layer for gravel (left) and clay (right). Modeled MAGT in gravel increase linearly for increasing ground thickness (note the logarithmic $x$ axis), while MAGT in clay are constant for $d z_{\min } \leq 20 \mathrm{~mm}$. The sensitivity to $d z_{\min }$ decreases for ground temperatures closer to $0^{\circ} \mathrm{C}$ (bottom figures).

conduction and the Richards equation should be solved at maximally half-hour resolution. Hourly resolution leads to average differences of around $0.2^{\circ} \mathrm{C}$ in the solutions. The sensitivity to $d t$ increases linearly with increasing $d t$, with changes of $0.8^{\circ} \mathrm{C}$ for a resolution of $4 \mathrm{~h}$ in average.

\section{Snow}

The number of top layers in the snow module should be set to at least two, and the maximal value of $\mathrm{swe}_{\mathrm{m}}$ should not exceed $10 \mathrm{~mm}$ to ensure stable ground temperatures. A few individual locations react nonlinearly to changes in the snow discretization parameters. We were, however, not able to explain the nonlinear response at these individual points.

All discretization parameters converge to stable solutions with average errors between 0.001 and $0.06^{\circ} \mathrm{C}$ between the finest resolutions, allowing for quantification of average discretization errors (Table 4). The initial ground temperature is not sensitive under all environmental conditions, which indicates that the ground initialization is reliable.

\subsubsection{Model-specific parameters}

The calibrated LDR parameterization by Konzelmann et al. (1994) results in difference of 0.6 to $1.2^{\circ} \mathrm{C}$ with respect to the published, original value of the parameterization. Neglecting the water balance results in changes of $1.5^{\circ} \mathrm{C}$ in MAGST in sandy ground, while for rock or clay, the water balance is not important. Hence, in these ground types, the water balance might be neglected to save computational time. The Richard tolerance, which influences the convergence of the Richard's equation for movement of liquid water in ground, is important in gravel (more than $0.5^{\circ} \mathrm{C}$ ), whereas for the other ground types it is insignificant. When modeling ground with high hydraulic conductivity, the tolerance of the Richard's equation should be set sufficiently small (e.g., $10^{-8}$ ).

\subsubsection{Physical parameters influencing the energy balance}

The dry ground albedo is the most sensitive parameter. Depending on the location, the sensitivity to the dry ground albedo (0.1 to 0.4$)$ varies from around 0.5 to more than $2.5^{\circ} \mathrm{C}$ for clay, for example. It is greatest at south-exposed slopes, and decreases by around $1.3^{\circ} \mathrm{C}$ at north-exposed slopes. A slight decrease of the sensitivity is observed for $30^{\circ}$ steep slopes facing north, while $30^{\circ}$ south-facing slopes are more sensitive than flat slopes. The increased sensitivity stays in direct relation to the amount of solar radiation received at a locations. The sensitivity to the dry ground albedo increases strongly with decreasing elevation for all ground types because the snow duration is shorter at low-elevation sites. The minimal MAGT change is $0.5^{\circ} \mathrm{C}$ at high elevation, inclined north-exposed slopes, while the maximal sensitivity to the dry ground albedo varies from 2.5 (clay, silt) to almost $4{ }^{\circ} \mathrm{C}$ (rock and gravel) (Fig. 9). The wet ground albedo is less sensitive than the dry ground albedo for all ground types. It ranges from 0.2 (gravel, sand, peat) to $1.3{ }^{\circ} \mathrm{C}$ (rock). In GEOtop, the value of the wet ground albedo is used if the water content equals $\theta_{\text {sat. }}$. Since $\theta_{\text {sat }}$ is very small in rock, the value of the wet albedo is more important than for other ground types, which explains its higher sensitivity. That simplification leads to the greater sensitivity of rock to the wet ground albedo, which in reality is likely not the case. The snow height for which the snow-ground albedo is interpolated has a maximal sensitivity of more than $1{ }^{\circ} \mathrm{C}$, very similar to the fresh snow albedo. In summary, the surface albedo determined either by snow, ground or a composition of both has the greatest influence on MAGT. This supports the importance of the solar radiation in the energy balance determining snow melt and the available energy warming the ground in this environment.

Ground roughness changes MAGT at $1 \mathrm{~m}$ depth maximally by around 1.2 to $2^{\circ} \mathrm{C}$ (rock). The height of the wind velocity meteorological station, the Monin-Obhukov parameterization and the dew point temperature lapse rate result in differences of around $1{ }^{\circ} \mathrm{C}$ in MAGT. Turbulent fluxes as well as longwave radiation have an increased importance during the night, when no radiation from the Sun reaches Earth. Snow roughness is less important $\left(0.5^{\circ} \mathrm{C}\right)$ than ground roughness since the snow surface is more homogeneous. 


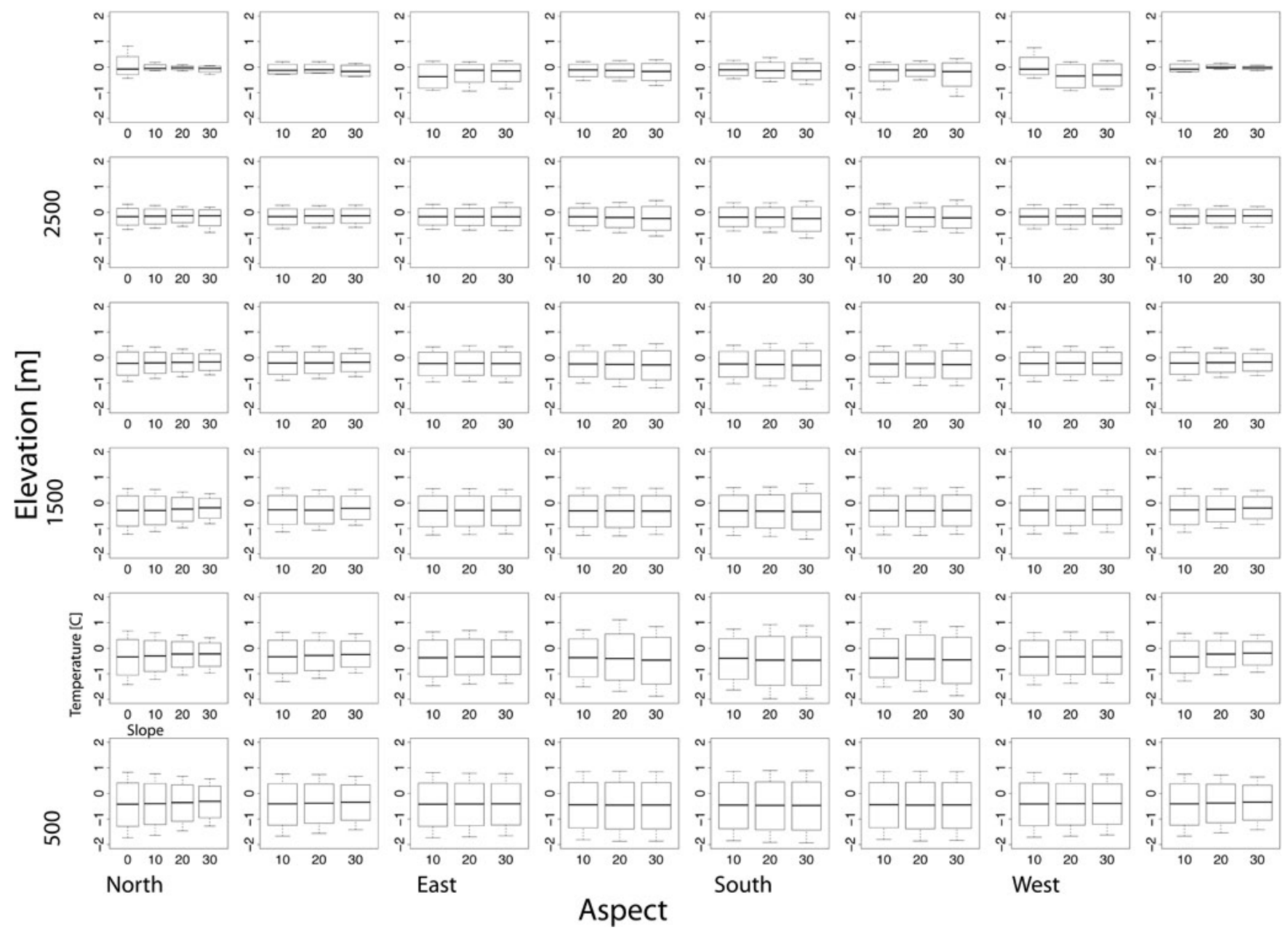

Fig. 7. Small multiple plots of normalized box plots of MAGT at $1 \mathrm{~m}$ depth $\left[{ }^{\circ} \mathrm{C}\right]$, simulated at all topographic locations for different ground albedo values. The box plots represent the different model outputs. The length of the $95 \%$ uncertainty range of each box plot indicates the sensitivity to dry ground albedo at each location.

Table 4. Average discretization error $\varepsilon\left[{ }^{\circ} \mathrm{C}\right]$ of MAGT modeled at $1 \mathrm{~m}$ depth due to the different discretization parameters.

\begin{tabular}{|c|c|c|c|c|c|c|c|c|c|c|c|}
\hline $\begin{array}{l}d t \\
\varepsilon_{d t}\end{array}$ & $\begin{array}{l}1800 \\
0 \\
\end{array}$ & $\begin{array}{l}3600 \\
0.027 \\
\end{array}$ & $\begin{array}{l}7200 \\
0.113 \\
\end{array}$ & $\begin{array}{l}14400 \\
0.226\end{array}$ & & & & & & & \\
\hline$n_{\mathrm{m}}$ & 64 & 32 & 16 & 8 & 4 & 2 & 1 & & & & \\
\hline$\varepsilon_{n_{\mathrm{m}}}$ & 0 & 0 & 0 & 0.001 & 0.013 & 0.004 & 0.023 & & & & \\
\hline $\mathrm{swe}_{\mathrm{m}}$ & 1.25 & 2.5 & 5 & 10 & 20 & 40 & & & & & \\
\hline$\varepsilon_{\mathrm{swe}_{\mathrm{m}}}$ & 0 & -0.025 & -0.032 & -0.02 & 0.093 & 0.225 & & & & & \\
\hline$n_{\mathrm{b}}$ & 10 & 9 & 8 & 7 & 6 & 5 & 4 & 3 & 2 & 1 & \\
\hline$\varepsilon_{n_{\mathrm{b}}}$ & 0 & 0 & 0 & 0 & 0 & 0 & 0 & 0 & 0 & 0.001 & \\
\hline$n_{\mathrm{t}}$ & 10 & 9 & 8 & 7 & 6 & 5 & 4 & 3 & 2 & 1 & \\
\hline$\varepsilon_{n_{\mathrm{t}}}$ & 0 & 0 & 0 & 0 & 0 & 0.001 & 0.002 & 0.004 & 0.004 & 0.172 & \\
\hline$d z_{\min }$ & 5 & 10 & 20 & 40 & 80 & 160 & 320 & 640 & & & \\
\hline$\varepsilon_{d z_{\min }}$ & 0 & 0.061 & 0.138 & 0.231 & 0.444 & 0.749 & 1.11 & 1.535 & & & \\
\hline$z_{\max }$ & 20000 & 10000 & 5000 & 2500 & 1250 & & & & & & \\
\hline$\varepsilon_{z_{\max }}$ & 0 & -0.004 & -0.001 & -0.002 & -0.098 & & & & & & \\
\hline$b$ & 1 & 1.1 & 1.2 & 1.3 & 1.4 & 1.5 & 1.6 & 1.7 & 1.8 & 1.9 & 2 \\
\hline$\varepsilon_{\mathrm{b}}$ & 0 & -0.001 & 0.002 & 0.001 & -0.006 & -0.003 & -0.001 & -0.001 & -0.033 & -0.022 & -0.014 \\
\hline
\end{tabular}



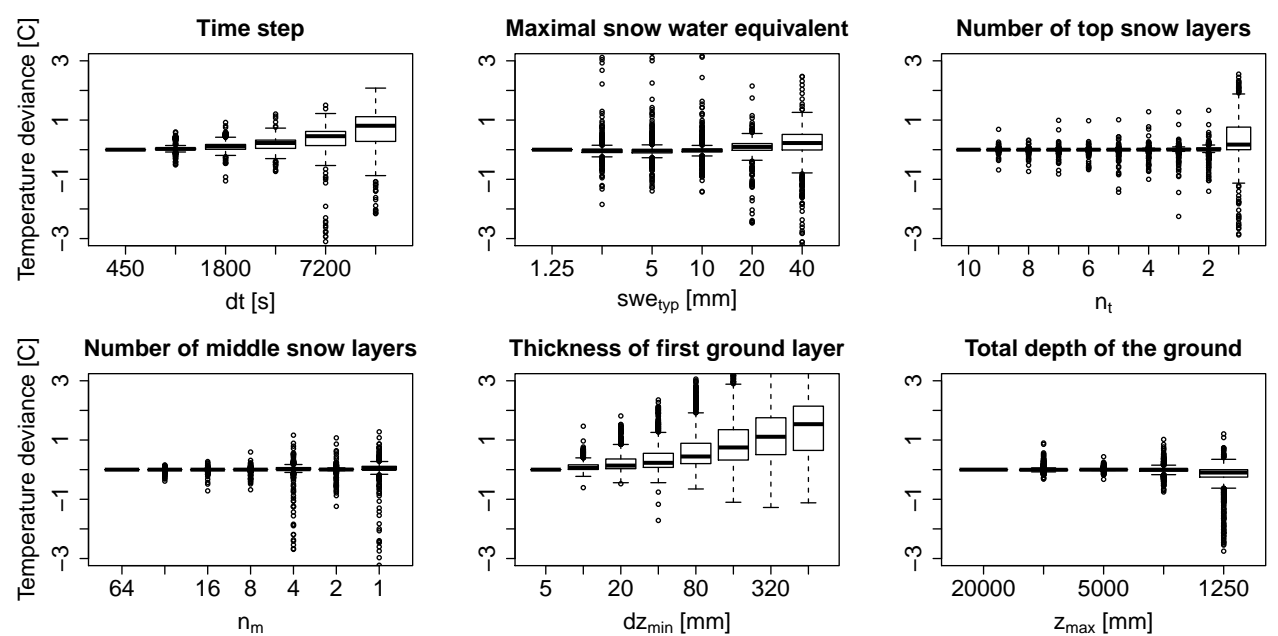

Fig. 8. Sensitivities of MAGT modeled at $1 \mathrm{~m}$ depth to the six sensitive discretization parameters $d_{\mathrm{t}}$ (top left), swe $\mathrm{m}_{\mathrm{m}}$ (top middle), $n_{\mathrm{t}}$ (top right), $n_{\mathrm{m}}$ (bottom left), $d z_{\min }$ (bottom middle) and $z_{\max }$ (bottom right), normalized with MAGT modeled with the finest resolution of each parameter. The sensitivities are summarized as box plots for all topographic properties and the six ground types.

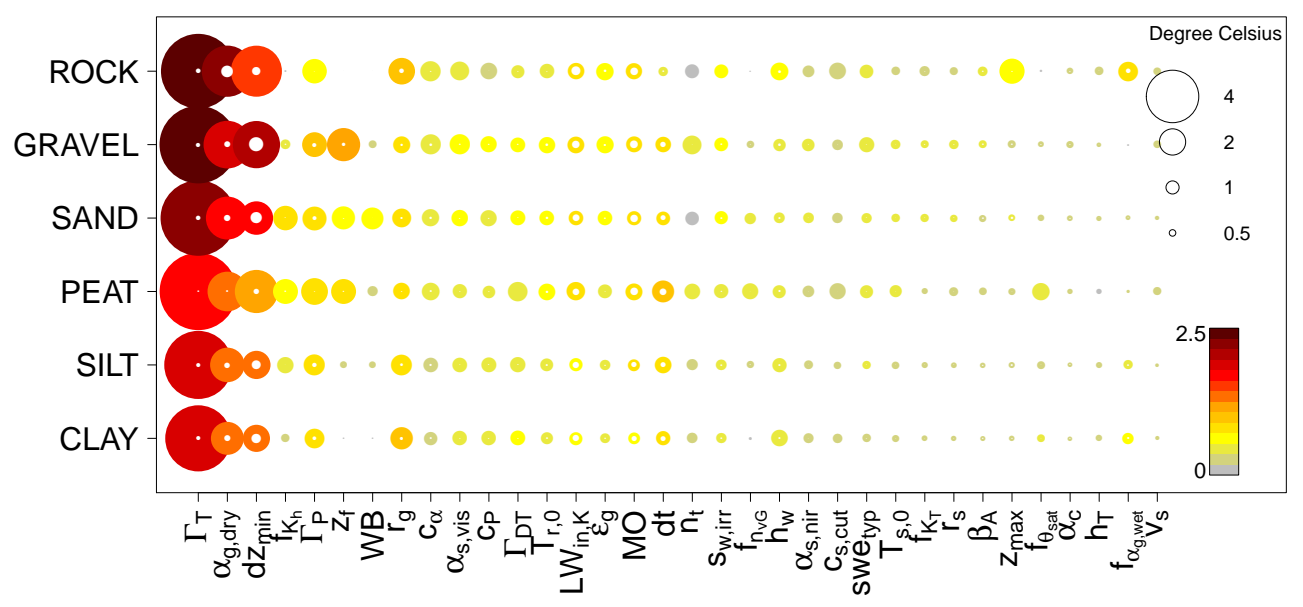

Fig. 9. Sensitivities of topographic sensitivity summarized as the 5, 50 and $95 \%$ percentiles of MAGT modeled at $1 \mathrm{~m}$ depth for all ground types. The area of the circle indicates the $95 \%$ percentile, and the area of the white dot the $5 \%$ percentile of the sensitivity, summarized for all topographic locations. The color indicates the median sensitivity.

Other parameters such as temperature threshold for snow, the thermal conductivity, the Ångström parameter $\beta$ and the snow viscosity change MAGT by around $0.5^{\circ} \mathrm{C}$. The remaining parameters have a maximal sensitivity that is less than $0.5^{\circ} \mathrm{C}$ for all studied locations and ground types. These parameters, as well as the very sensitive parameters, were excluded from the subsequent comprehensive uncertainty analysis to reduce the parameter space.

\subsubsection{Hydraulic properties of different ground types}

The sensitivity of parameters influencing the water content in the ground such as the hydraulic conductivity $K_{\mathrm{h}}$, the surface above which all water drains $z_{f}$, the saturated water content and the van Genuchten parameter $n$ vary strongly for the different ground types (Fig. 9). The sensitivities range from 0.2 (rock) to $2{ }^{\circ} \mathrm{C}$ (sand and peat) differences at $1 \mathrm{~m}$ depth for $z_{f}$, from 0.3 (rock) to 0.5 (clay, sand, gravel) to $1.2^{\circ} \mathrm{C}$ (peat) for $\theta_{\mathrm{sat}}$, and from 0.2 (rock) to $1.2^{\circ} \mathrm{C}$ (peat) for $n_{\mathrm{vG}}$.

\subsection{Uncertainties in modeled MAGT}

Two arguments support the parameter selection for the uncertainty analysis: (a) we exclude all numerical, discretization and model specific parameters since these parameters add to model error and not to model uncertainty and (b) include only parameters that influence ground temperature for more than $0.5^{\circ} \mathrm{C}$ and at least one ground type (Fig. 9). All other 


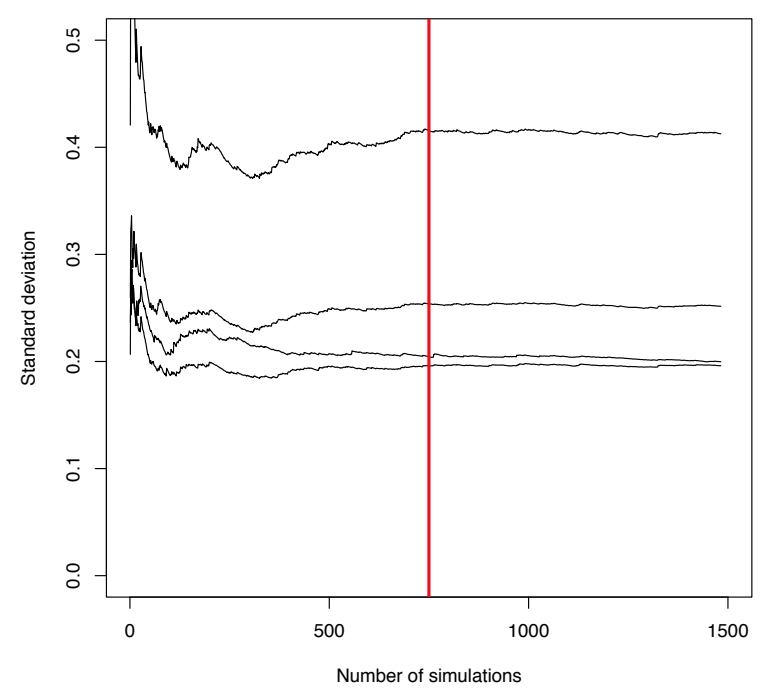

Fig. 10. Standard deviation of the model MAGT at $10 \mathrm{~cm}$ depth for increasing number of simulations (sand) at four arbitrarily selected points. Convergence is reached at approximately 750 simulations (indicated by the red line).

parameters are fixed at their baseline value. The remaining parameters are sampled randomly according to their prior distribution (Table 3). In total, 1500 simulations were run; however 750 would suffice to ensure convergence (Fig. 10).

A plot of the frequency histograms at a location at $3500 \mathrm{~m}$ for the different depths is given in Fig. 11 (in the year 2010). At $10 \mathrm{~m}$ depth, we observe a non-Gaussian temperature distribution with values mostly below the freezing point of water. Closer to the surface, the simulated temperatures are higher than $0^{\circ} \mathrm{C}$. Since the initialization (1995-2000) of the ground temperature was done in a period of cold air temperatures, the ground was frozen. In the time after, air temperatures increased and the ground thawed. However, not enough energy was available to melt the ground column down to the bottom, which we observe in the distribution of the simulations at the lowest node. We can see that if ground temperatures are close to the freezing point, the frequency histogram of model simulations may be non-Gaussian. For this reason, the parametric model output uncertainty is expressed as the length of the $95 \%$ uncertainty interval.

The parametric uncertainty varies from 0.4 to $1.5^{\circ} \mathrm{C}$ for MAGT modeled in clay and silt. It is higher in sand, peat, gravel and rock (Fig. 12). In rock, the uncertainty decreases with increasing depth, as would be expected if integrating over a larger surface area. The increased uncertainty in sand, peat and gravel underlines the importance of accurate estimates of the hydraulic properties in these ground types. The parametric output uncertainty decreases for increasing elevation for all ground types. This can be attributed to the increased sensitivity to parameters influencing the energy balance at low-elevation sites, i.e., the ground albedo or
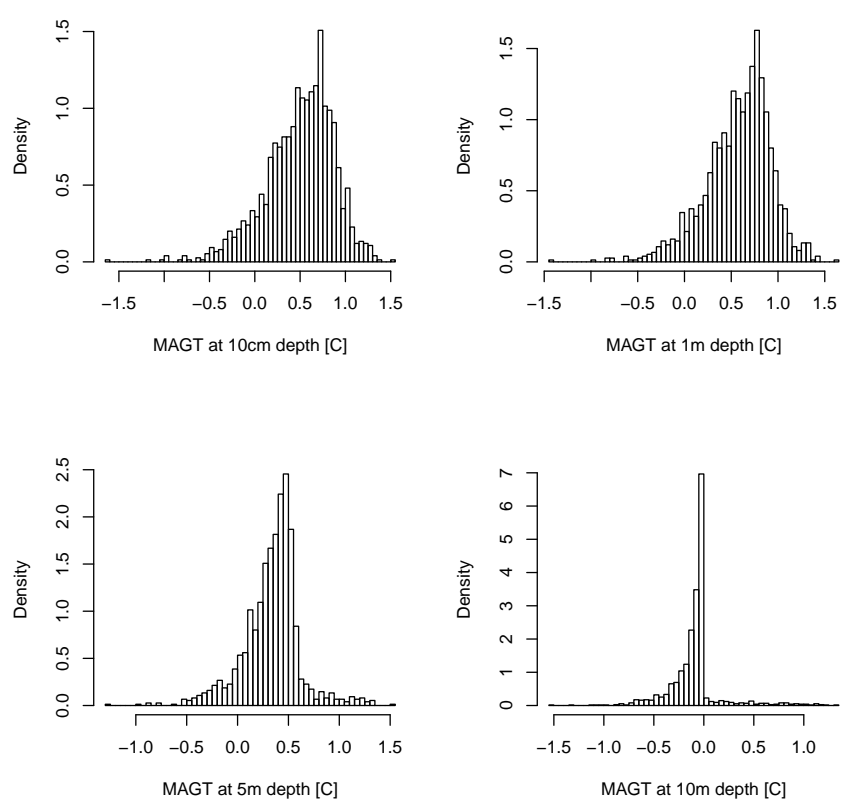

Fig. 11. Density histograms of modeled MAGT at a north-facing slope at $3500 \mathrm{~m}$ elevation at the four depths. At the greatest depths (right bottom), the soil remains frozen for most of the simulations, which indicates a cold initialization period. At points closer to the surface, the soil has thawed for most simulation.

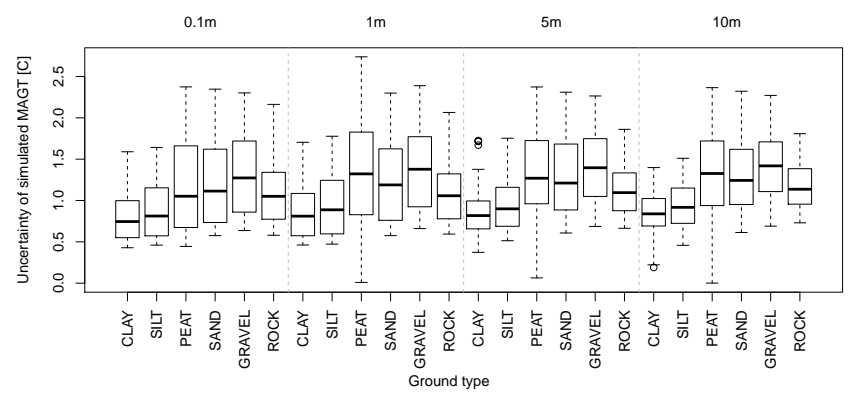

Fig. 12. Boxplots of the total output uncertainty for all topographic locations, presented for all ground types and depths. The parametric uncertainty is increased for sand, peat, gravel and rock.

roughness (Sect. 4.2). The environmental variability of the model uncertainties is not as pronounced as in the sensitivities, but differences between individual locations can still be observed.

Ground temperatures at greater depths integrate over larger surface areas (Gold and Lachenbruch, 1973), and are hence expected to be less variable than at the surface. Since the heat conduction is solved in one dimension in GEOtop, integration over large areas is not represented in these simulations. This may explain the constant size of the uncertainties at different depths. To study the influence of depth on model uncertainties, an uncertainty analysis should be performed solving the heat conduction in three dimensions. 
However, the spatial autocorrelation of the parameters would have to be taken into account.

Model uncertainty at the surface is comparable with variability of ground surface temperatures measured within $10 \mathrm{~m} \times 10 \mathrm{~m}$ cells. These range from approximately 0.25 at homogeneous grass sites to $2.5^{\circ} \mathrm{C}$ in block fields, expressed as the total range (Gubler et al., 2011). The fine-scale environmental variability is similar to the parametric uncertainty found for modeled MAGT at $10 \mathrm{~cm}$ depth.

\section{Discussion}

\subsection{The relevance of representative model evaluation}

The synthetic environment allowed for us to quantify model sensitivity and uncertainty under differing environmental conditions. The selected setting allowed for quantification of the influence of individual parameters for different environmental conditions, as well as identification of locations where model sensitivities and uncertainties are largest. These findings can inform future measurement campaigns. Model uncertainty (for a given location, time and variable) can be interpreted as one metric for the benefit of an individual measurement. It does, however, not provide information on the correspondence of model results with reality, and should therefore be treated with care, and as one of several metrics to inform the design of measurement campaigns. Spatially distributed ground albedo measurements would, especially at low-elevation and south-exposed sites, strongly decrease the uncertainty of mountain permafrost models, and result in more-accurate model outputs. Other parameters are sensitive only under specific conditions, such as, for example, the hydraulic properties of the ground. A study on rock faces alone results in an insignificant influence of the hydraulic properties on modeled ground temperatures. Applied to other ground types such as sand, peat or gravel, this conclusion that the hydraulic properties are insignificant is wrong. Hence, evaluation of spatially distributed models should cover the main environmental properties of the modeling domain, since otherwise important model features could be missed. A recent study obtained similar results concerning the variability of model sensitivities and uncertainties due to differing topographic and climatic conditions for a snow model (He et al., 2011).

Thus, the presented environmental setting allowed for us to draw representative conclusions about the sensitivity and uncertainties of modeled MAGT in mountain regions. The results could be extended to modeling lowland areas, where the environmental variability may be, for example, expressed as differences in vegetation. The study contributes to the request by Gupta et al. (2008) for more representative model evaluation.

\subsection{Sensitivities and uncertainties of the physically based model GEOtop}

Snow is important in determining the thermal state of the ground (Goodrich, 1982; Keller and Gubler, 1993; Ishikawa, 2003; Luetschg et al., 2008). Parameters such as the temperature lapse rate or the correction factor for the precipitation measurement strongly influence snow duration, but have opposite effects. A higher lapse rate, for example, leads to warmer air temperature at low-elevation sites (if the meteorological station is located above the simulated locations), and results hence in faster melt-out. This is compensated by enhanced snow accumulation due to a greater precipitation lapse rate or higher precipitation correction factor. This compensating effect between different parameters is widely known as equifinality (Beven and Freer, e.g., 2000). A similar result was obtained by Essery and Etchevers (2004) for the influence of the radiative and turbulent fluxes on snow melt, for which different parameter combinations provided equally well behaving model outputs. Combination of different measured quantities could reduce the problem and lead to arguments for model improvement if conflicting results are obtained (Essery and Etchevers, 2004). GEOtop, and probably any physically based permafrost model, would benefit from validation with distributed time series of snow height (or SWE) in order to distinguish between snow accumulation and melting processes. Similarly, mountain permafrost models could benefit from individual calibration of parameters influencing the energy balance such as the roughness length (e.g., Andreadis et al., 2009) or ground albedo (e.g., Hoelzle, 1996; Gruber, 2005).

The ground albedo, which determines the net shortwave radiation at Earth's surface in summer, was the most important parameter when modeling MAGT. The importance of ground albedo in permafrost models has already been investigated by Hoelzle (1996), Ling and Zhang (2004) and Gruber (2005). Similarly, snow albedo is important since it strongly influences snow melting (Etchevers et al., 2004). Here, changes in the snow albedo changed MAGT by around $1^{\circ} \mathrm{C}$. The parameters influencing the turbulent fluxes determine snow melt (e.g., Etchevers et al., 2004) and change MAGT by around 0.5 to $1.5^{\circ} \mathrm{C}$. Calibration of the Konzelmann et al. (1994) LDR parameterization (e.g., Gubler et al., 2012) changes MAGT also by around $1^{\circ} \mathrm{C}$. This supports the relevance of calibrating physically based models (e.g., Beven and Binley, 1992; Gupta et al., 1998), and underlines the importance of evaluating individual processes separately if used in impact models, as, for example, done by StockerMittaz et al. (2002) for mountain permafrost research. Some of the discretization parameters such as the time step at which equations are solved, as well as the thickness of the ground and snow-pack layers change MAGT by more than $1{ }^{\circ} \mathrm{C}$. The temporal resolution should optimally be half an hour to ensure an error of less than $0.1^{\circ} \mathrm{C}$. Thickness of the uppermost ground layer of $20 \mathrm{~mm}$ results in $0.1^{\circ} \mathrm{C}$ difference from the 
smallest discretization chosen (e.g., $5 \mathrm{~mm}$ ). The findings concerning the time step and the thickness of the uppermost soil layer are comparable to the findings by Romanovsky et al. (1997), who compared the behavior of three numerical permafrost models with analytical solutions of the heat conduction.

The sensitivity of the hydraulic parameters that determine the shape of the water retention curve varies strongly for the different ground types. For clay and rock, the sensitivity is almost negligible, while for sand or gravel, the van Genuchten parameter $n, \theta_{\text {sat }}$ and the hydraulic conductivity play a major role. Seaman et al. (2009) found that $n, \theta_{\text {sat }}$ and $\theta_{\text {res }}$ are the most important parameters to predict water retention in sand. The hydraulic conductivity $K_{\mathrm{h}}, \theta_{\text {sat }}$ and $\theta_{\text {res }}$ were most important to estimate ground moisture in Mertens et al. (2005), while Jhorar et al. (2002) recommended fitting $\alpha, n$ and $\theta_{\text {sat }}$ when using the van Genuchten parameterization. The sensitivity of the van Genuchten parameters are hence controversial in the literature (e.g., Pollaco and Mohanty, 2012). In this study, we found that the hydraulic conductivity, the shape parameter $n$ and the porosity most strongly influence MAGT for sand, peat and gravel. The variable sensitivity observed for the different soil types may by a reason for the controversial sensitivities found in the literature. These results underline the importance of systematic model evaluation for different environmental settings, since otherwise important model features are missed and would lead to wrong conclusions. Extrapolation of model uncertainties to locations of different environmental conditions is not feasible unless a systematic analysis spanning the environmental variability is performed.

The total parametric uncertainty goes from 0.5 to $1.5^{\circ} \mathrm{C}$ for clay and silt, and increases up to around $2.4^{\circ} \mathrm{C}$ for peat, sand, gravel and rock. This underlines the importance of hydraulic properties of ground types having high hydraulic conductivity and high porosity. In general, uncertainty is greater at low-elevation sites since the sensitivity to the ground albedo, as well as the turbulent fluxes, increases at lowelevation sites. Parametric uncertainty of MAGT at different depth is almost constant. The parametric model uncertainty is comparable to small-scale environmental variability of ground surface temperatures measured in Switzerland (Gubler et al., 2011).

This analyses performed in this study are of theoretical and practical relevance. The synthetic model setting allowed for quantification of the variability of model uncertainties within highly variable terrain as typically encountered when modeling mountain permafrost. To use GEOtop operationally, it should, however, be validated with spatially distributed measurements after an in-depth evaluation of all processes in the field. The diverse model parameters should be calibrated to local conditions to increase the accuracy of the model. Combination of both uncertainty and validation studies would provide additional insights on the model's ability to reproduce the processes that are relevant for mountain permafrost.

\section{Conclusions}

\subsection{Environmental variability}

Sensitivity and uncertainty studies are widely known to inform model use and model improvement. We have shown that model sensitivities and uncertainties can vary strongly as a function of the geographic location at which the modeling study is performed. The results support the importance of systematic and representative model evaluation (e.g., Gupta et al., 2008) such as to evaluate models within a setting that represents typical situations of the modeling domain. The systematic setting allows for comparison of our physical understanding of key processes for a variety of test cases. We conclude that considering environmental variability when analyzing model uncertainties is important to gain confidence in the conclusions made about the model and the modeled outputs. Before applying a model in a certain setting, a modeler should therefore determine the most important environmental variables (topography, differing soils, plants, etc.) that may influence model outputs. However, it is also important to note that in determining the most important variables, the modeler makes assumptions about how to abstract particular processes that may not reflect reality. Nonetheless, by carrying out a systematic model assessment, it is possible to evaluate the influence of model parameters on the processes being represented.

Based on these input factors that represent the modeling domain, a systematic model assessment should be undertaken. Otherwise, if model evaluation is done at few points in the modeling domain, important model features might be missed, and misleading conclusions might be drawn. For example, model sensitivities assessed at a south-exposed location might lead to an overestimation of the sensitivity to ground albedo in comparison to north-exposed locations. The possibility of detecting model deficiencies is increased when systematic and representative model evaluations are performed. The methods presented in this study proved useful in the study of the uncertainties of a distributed physical model used in mountain permafrost research within highly variable terrain. The high computational effort undertaken by simulating all combinations of environmental variables provided reliable results. The effort could, for future studies, however be reduced by using a probabilistic approach (e.g., Latin hypercube sampling).

\subsection{GEOtop sensitivities and uncertainties}

Uncertainties in modeled MAGT mainly come from uncertainties in the snow conditions and the individual components of the energy balance. The sensitivities are highly variable in variable topographies. To improve modeling results, spatially distributed measurements of snow, the components of the energy balance and ground conditions are required at locations of greatest uncertainties. These uncertainties 
include both modeling and measurement uncertainties due to heterogenous environmental conditions (e.g., Gubler et al., 2011). These spatially distributed measurements should be used to validate and calibrate physically based models such as GEOtop in order to improve the general ability to model ground temperatures in mountain regions.

Accurate estimates of the hydraulic properties are required for soil types peat, sand and gravel to reduce MAGT modeled with GEOtop. While the result about the sensitivity of the soil types may differ for other permafrost models, it again underlines the importance of a representative model evaluation setting. Finally, missing processes, such as advection in blocky terrain, should be integrated into future versions of GEOtop.

Acknowledgements. We would like to thank R. Essery, M. Hoelzle and an anonymous referee for their constructive comments, which helped to improve this manuscript. This work was supported by the AAA/SWITCH-funded Swiss Multi-Science Computing Grid project (www.smscg.ch) with computational infrastructure and support. Customized libraries (ggeotop and GC3Pie) and user support were kindly provided by GC3: Grid Computing Competence Center (www.gc3.uzh.ch). The authors are grateful for the support by S. Maffioletti, who patiently answered any questions concerning the grid computing. This project was funded by the Swiss National Science Foundation (SNSF) via the NCCR MICS project PermaSense and via the project X-Sense (www.nano-tera.ch). All statistical analyses were performed with $\mathrm{R}$ (www.cran.r-project.org). We thank MeteoSwiss for supporting the work financially during the reviewing process.

Edited by: P. Huybrechts

\section{References}

AIAA: Guide for the verification and validation of computational fluid dynamics simulations, American Institute of Aeronautics and Astronautics, Reston, VA, USA, 1998.

Anderson, M. G. and Bates, P. D. (Eds).: Model Validation: Perspectives in Hydrological Science, Wiley, New York, USA, 2001.

Andreadis, K. M., Storck, P., and Lettenmaier, D. P.: Modeling snow accumulation and ablation processes in forested environments, Water Resour. Res., 45, W05429, doi:10.1029/2008WR007042, 2009.

Ångström, A.: The albedo of various surfaces of ground, Geograf. Ann., 7, 323-342, 1925.

Barringer, J. R. F.: A variable lapse rate snowline model for the remarkables, Central Otago, New Zealand, J. Hydrol., 28, 3246, 1989.

Beck, M. B.: Water quality modeling: a review of the analysis of uncertainty, Water Resour. Res., 23, 1393-1442, 1987.

Beck, M. B., Ravetz, J. R., Mulkey, L. A., and Barnwell, T. O.: On the problem of model validation for predictive exposure assessments, Stoch. Hydrol. Hydraul., 11, 229-254, 1997.

Bertoldi, G., Rigon, R., and Over, T. M.: Impact of watershed geomorphic characteristics on the energy and water budgets, J. Hydrometeorol., 7, 389-403, 2006.
Beven, K.: Prophecy, reality and uncertainty in distributed hydrological modelling, Adv. Water Resour., 16, 41-51, 1993.

Beven, K. and Binley, A.: The future of distributed models: model calibration and uncertainty prediction, Hydrol. Process., 6, 279 298, 1992.

Beven, K. and Freer, J.: Equifinality, data assimilation, and uncertainty estimation in mechanistic modelling of complex environmental systems using the GLUE methodology, J. Hydrol., 249, 11-29, 2000

Brutsaert, W.: On a derivable formula for long-wave radiation from clear skies, Water Resour. Res., 11, 742-744, 1975.

Carey, S. K., Quinton, W. L., and Goeller, N. T.: Field and laboratory estimates of pore size properties and hydraulic characteristics for subarctic organic soils, Hydrol. Process., 21, 2560-2571, doi:10.1002/hyp.6795, 2007.

Cermák, V. and Rybach, L.: Thermal conductivity and specific heat of minerals and rocks, in: Landolt-Börnstein Zahlenwerte und Funktionen aus Naturwissenschaften und Technik, Physikalische Eigenschaften der Gesteine, Springer, New York, 305-343, 1982.

Chen, M. H., Shao, Q. M., and Ibrahim, J. G.: Monte Carlo Methods in Bayesian Computation, Springer Verlag, New York, 2000.

Crosetto, M. and Tarantola, S.: Uncertainty and sensitivity analyses: tools for GIS-based model implementation, Int. J. Geograph. Inf. Sci., 15, 415-437, 2001.

Cukier, R. I., Levine, H. B., and Shuler, K. E.: Nolinear sensitivity analysis of multiparameter model systems, J. Phys. Chem., 81, 2365-2366, 1977.

Dall'Amico, M.: Coupled water and heat transfer in permafrost modeling, Ph.D. Thesis, Institute of Civil and Environmental Engineering, Universita degli Studi di Trento, Trento, 2010.

Davis, T. J. and Keller, C. P.: Modelling uncertainty in natural resource analysis using fuzzy sets and Monte Carlo simulation: slope stability prediction, Geogr. Inf. Sci., 11, 409-434, 1997.

Dozier, J. and Warren, S. G.: Effect of viewing angle on the infrared brightness temperature of snow, Water Resour. Res., 18, 1424 1434, 1982.

Endrizzi, S.: Snow cover modelling at local and distributed scale over complex terrain, Ph.D. thesis, Institute of Civil and Environmental Engineering, Universita degli Studi di Trento, Trento, 2007.

Essery, R. and Etchevers, P.: Parameter sensitivity in simulation of snowmelt, J. Geophys. Res., 109, D20111, doi:10.1029/2004JD005036, 2004.

Etchevers, P., Martin, E., Brown, R., Fierz, C., Lejeune, Y., Bazile, E., Boone, A., Dai, Y. J., Essery, R., Fernandez, A., Gusev, Y., Jordan, R., Koren, V., Kowalczyk, E., Nasonova, N. O., Pyles, R. D., Schlosser, A., Shmakin, A. B., Smirnova, T., Strasser, U., Verseghy, D., Yamazaki, T., and Yang, Z. L.: Validation of the energy budget of an alpine snowpack simulated by several snow models (SnowMIP project), Ann. Glaciol., 38, 150-158, 2004.

Etzelmüller, B., Hoelzle, M., Heggem, E. S. F., Isaksen, K., StockerMittaz, C., Ødegård, R. S., Haeberli, W., and Sollid, J. L.: Mapping and modelling the occurrence and distribution of mountain permafrost, Norsk Geograf. Tidsskr., 55, 186-194, 2001.

Gold, L. W. and Lachenbruch, A. H.: Thermal conditions in permafrost - a review of North American literature, in: Proceedings of the 2nd International Conference on Permafrost, Yakutsk, USSR, 3-25, 13-28 July 1973. 
Goodison, B. E., Louie, P. Y. T., and Yang, D.: WMO solid precipitation measurement intercomparison, Tech. Rep., World Meteorological Organization, Geneva, Switzerland, 1998.

Goodrich, L. E.: The influence of snow cover on the ground thermal regime, Can. Geotech. J., 19, 421-432, doi:10.1139/t82-047, 1982.

Gruber, S.: Mountain Permafrost: Transient Spatial Modelling, Model Verification and the Use of Remote Sensing, Ph.D. thesis, University of Zurich, Zurich, 2005.

Gruber, S. and Hoelzle, M.: The cooling effect of coarse blocks revisited: a modeling study of a purely conductive mechanism, in: 9th International Conference on Permafrost, Fairbanks, Alaska, 557-561, 28 June -3 July 2008.

Gubler, S., Fiddes, J., Keller, M., and Gruber, S.: Scaledependent measurement and analysis of ground surface temperature variability in alpine terrain, The Cryosphere, 5, 431-443, doi:10.5194/tc-5-431-2011, 2011.

Gubler, S., Gruber, S., and Purves, R. S.: Uncertainties of parameterized surface downward clear-sky shortwave and allsky longwave radiation., Atmos. Chem. Phys., 12, 5077-5098, doi:10.5194/acp-12-5077-2012, 2012.

Gupta, H. V., Sorooshian, S., and Patrice, O. Y.: Toward improved calibration of hydrologic models: Multiple and noncommensurable measures of information, Water Resour. Res., 34, 751-763, 1998.

Gupta, H. V., Beven, K., and Wagener, T.: Model Calibration and Uncertainty Estimation, John Wiley \& Sons, New York, 2005.

Gupta, H. V., Wagener, T., and Liu, Y.: Reconciling theory with observations: elements of a diagnostic approach to model evaluation, Hydrol. Process., 22, 3802-3813, 2008.

Haeberli, W.: Die Basis-Temperatur der winterlichen Schneedecke als möglicher Indikator für die Verbreitung von Permafrost in den Alpen, Z. Gletscherk. Glaziol., 9, 221-227, 1973.

He, M., Hogue, T. S., Franz, K. J., Margulis, S. A., and Vrugt, J. A.: Characterizing parameter sensitivity and uncertainty for a snow model across hydroclimatic regimes, Adv. Water Resour., 34, 114-127, 2011.

Hoelzle, M.: Mapping and modelling of mountain permafrost distribution in the Alps, Norsk Geograf. Tidsskr., 50, Ho11-15, 1996.

Hoelzle, M., Mittaz, C., Etzelmüller, B., and Haeberli, W.: Surface energy fluxes and distribution models of permafrost in European mountain areas: an overview of current developments, Permafrost Periglac. Process., 12, 53-68, 2001.

Hoelzle, M., Haeberli, W., and Mittaz, C.: Miniature ground temperature data logger measurements 2000-2002 in the MurtèlCorvatsch area, Eastern Swiss alps, in: 8th International Conference on Permafrost, Proceedings, edited by: Phillips, M., Springman, S., and Arenson, L., Swets \& Zeitlinger, Lisse, Zürich, 419424, 21-25 July 2003.

Hori, M., Aoki, T., Tanikawa, T., Motoyoshi, H., Hachikubo, A., Siugiura, K., Yasunari, T. J., Eide, H., Storvold, R., Nakajima, Y., and Takahashi, F.: In-situ measured spectral directional emissivity of snow and ice in the 8-14 $\mu \mathrm{m}$ atmospheric window, Remote Sens. Environ., 100, 486-502, 2006.

Idso, S. B.: A set of equations for full spectrum and 8 to $14 \mu \mathrm{m}$ and 10.5 to $12.5 \mu \mathrm{m}$ thermal radiation from cloudless skies, Water Resour. Res., 17, 295-304, 1981.

Ineichen, P., Guisan, O., and Perez, R.: Ground-reflected radiation and albedo, Solar Energy, 44, 207-214, 1990.
Ishikawa, M.: Thermal regine at the snow-ground interface and their implications for permafrost investigation, Geomorphology, 52, 105-120, 2003.

Jhorar, R. K., Bastiaanssen, W. G. M., Feddes, R. A., and Van Dam, J. C.: Inversely estimating soil hydraulic functions using evapotranspiration fluxes, J. Hydrol., 258, 198-213, 2002.

Jin, M. and Shunlin, L.: An improved land surface emissivity parameter for land surface models using global remote sensing observations, J. Climate, 19, 2867-2881, 2006.

Keller, F. and Gubler, H. U.: Interaction between snow cover and high mountain permafrost at Murtél Corvatsch, Swiss Alps, in: The Sixth International Conference on Permafrost, Beijing, 332337, 5-9 July, 1993.

Kelley, C. T.: Solving Nonlinear Equations with Newton's method, Society for Industrial and Applied Mathematics, SIAM, Philadelphia, USA, 2003.

Kienzle, S. W.: A new temperature based method to separate rain and snow, Hydrol. Process., 22, 5067-5085, 2008.

Kohl, T.: Transient thermal effects below complex topographies, Tectonophysics, 306, 311-324, 1999.

Konzelmann, T., van de Wal, R. S. W., Greuell, W., Bintanja, R., Henneken, E. A. C., and Abe-Ouchi, A.: Parameterization of global and longwave incoming radiation for the Greenland Ice Sheet, Global Planet. Change, 9, 143-164, 1994.

Legates, D. R. and DeLiberty, T. L.: Precipitation measurement biases in the United States, J. Am. Water Resour. Assoc., 29, 855861, doi:10.1111/j.1752-1688.1993.tb03245.x, 1993.

Ling, F. and Zhang, T.: A numerical model for surface energy balance and thermal regime of the active layer and permafrost containing unfrozen water, Cold Reg. Sci. Technol., 38, 1-15, 2004.

Luetschg, M., Lehning, M., and Haeberli, W.: A sensitivity study of factors influencing warm/thin permafrost in the Swiss Alps, J. Glaciol., 54, 696-704, 2008.

Maier, U., de Biase, C., Baeder-Bederski, O., and Bayer, P.: Estimation of Van Genuchten and preferential flow parameters by inverse modelling for large scale vertical flow constructed wetlands, Geophys. Res. Abstr., EGU General Assembly, p. 12916, Vienna, Austria, 2009.

Markvart, T. and Castañer, L.: Practical Handbook of Photovoltaics: Fundamentals and Applications, Elsevier, Amsterdam, 2003.

Medici, F. and Rybach, L.: Geothermal map of Switzerland 1995 (heat flow density), Matériaux pour la Géologie de la Suisse, Géophysique Nr. 30, Schweizerische Geophysikalische Kommision, 1995.

Mertens, J., Madsen, H., Kristensen, M., Jaques, D., and Feyen, J.: Sensitivity of soil parameters in unsaturated zone modeling and the relation between effective, laboratory and in situ measurements, Hydrol. Process., 19, 1611-1633, 2005.

Monin, A. S. and Obukhov, A. M.: Basic laws of turbulent mixing in the surface layer of the atmosphere, Tr. Akad. Nauk SSSR Geophiz. Inst., 24, 163-187, 1954.

Nötzli, J., Gruber, S., Kohl, T., Salzmann, N., and Haeberli, W.: Three-dimensional distribution and evolution of permafrost temperatures in idealized high-mountain topography, J. Geophys. Res., 112, F02S13, doi:10.1029/2006JF000545, 2007.

Obukhov, A. M.: Turbulence in an atmosphere with a non-uniform temperature, Bound.-Lay. Meteorol., 2, 7-29, 1946.

Ogawa, K. and Schmugge, T.: Mapping surface broadband emissivity of the Sahara desert using ASTER and 
MODIS data, Earth Interact., 8, 1-14, doi:10.1175/10873562(2004)008<0001:MSBEOT>2.0.CO;2, 2004.

Pollaco, J. A. P., and Mohanty, B. P.: Uncertainties of water fluxes in soil-vegetation-atmosphere transfer models: inverting surface soil moisture and evapotranspiration retrieved from remote sensing, Vadose Zone J., 11, vzj2011.0167, doi:10.2136/vzj2011.0167, 2012.

Polo, J., Martín, L., and Cony, M.: Revision of ground albedo estimation in Heliosat scheme for deriving solar radiation from SEVIRI HRV channel of Meteosat satellite, Solar Energy, 86, 275282, 2012.

Prata, A. J.: A new long-wave formula for estimating downward clearsky radiation at the surface, Q. J. R. Meteorol. Soc., 122, 1127-1151, 1996.

Quinton, W. L., Hayashi, M., and Carey, S. K.: Peat hydraulic conductivity in cold regions and its relation to pore size and geometry, Hydrol. Process., 22, 2829-2837, doi:10.1002/hyp.7027, 2008.

Rigon, R., Bertoldi, G., and Over, T. M.: GEOtop: a distributed hydrological model with coupled water and energy budget, J. Hydrometeorol., 7, 371-388, 2006.

Romanovsky, V. E., Osterkamp, T. E., and Duxbury, N. S.: An evaluation of three numerical models used in simulations of the active layer and permafrost temperature regimes, Cold Reg. Sci. Technol., 26, 195-203, 1997.

Rykiel, J. E. J.: Testing ecological models: the meaning of validation, Ecol. Model., 90, 299-244, 1996.

Saltelli, A., Tarantola, S., and Campolongo, F.: Sensitivity Analyses in Practice, doi:10.1002/0470870958, John Wiley and Sons, New York, 2004.

Saltelli, A., Ratto, M., Andres, T., Campolongo, F., Cariboni, J., Gatelli, D., Saisana, M., and Tarantola, S.: Global Sensitivity Analysis, The Primer, John Wiley \& Sons, New York, 2008.

Scharmer, K. and Greif, J.: The European Solar Radiation Atlas, Vol. 1: Fundamentals and Maps, Les Presses de l'École des Mines, Paris, France, 2000.

Schmid, M.-O., Gubler, S., Fiddes, J., and Gruber, S.: Inferring snowpack ripening and melt-out from distributed measurements of near-surface ground temperatures, The Cryosphere, 6, 11271139, doi:10.5194/tc-6-1127-2012, 2012.

Seaman, J., Singer, J., and Aburime, S.: Evaluating the relative importance of the van Genuchten-Mualem parameters, in: Proceedings of the 2009 Georgia Water Resources Conference, 2729 April 2009.
Sobol, I. M.: Sensitivity analysis for non-linear mathematical model, Math. Model. Comput. Exp., 1, 407-414, 1993.

Stocker-Mittaz, C., Hoelzle, M., and Haeberli, W.: Modelling alpine permafrost distribution based on energy-balance data: a first step, Permafrost Periglac. Process., 13, 271-282, doi:10.1002/ppp.426, 2002.

Stow, C., Jollif, J., McGillicuddy Jr., D. J., Doney, S. C., Allen, J. I., Friedrichs, M. A. M., Rose, K. A., and Wallhead, P.: Skill assessment for coupled biological/physical models of marine systems, J. Mar. Syst., 76, 4-15, 2009.

Sutherland, R. A.: Broadband and spectral emissivities $(2-18 \mu \mathrm{m})$ of some natural soils and vegetation, J. Atmos. Ocean. Technol., 3, 199-202, 1986.

Tarboton, D. G. and Luce, C. H.: Utah Energy Balance Snow Accumulation and Melt Model (UEB), Tech. rep., Utah Water Research Laboratory Utah State University and USDA Forest Service Intermountain Research Station, Utah, USA, 1996.

Tetzlaff, G.: Albedo of the Sahara, in: Satellite measurements of radiation budget parameters, edited by: Raschke, E., 60-63, Bonn, 1983.

Tufte, E.: The Visual Display of Quantitative Information, Graphics Press, Cheshire, Connecticut, USA, 1983.

Tufte, E.: Envisioning Information, Graphics Press, Cheshire, Connecticut, USA, 1990.

Twarakavi, N. K. C., Simunek, J., and Schaap, M. G.: Can texture-based classification optimally classify soils with respect to soil hydraulics?, Water Resour. Res., 46, doi:10.1029/2009WR007939, 2010.

van Genuchten, M. T.: A closed-form equation for predicting the hydraulic conductivity of unsaturated soils, Soil Sci. Soc. Am. J., 44, 892-898, 1980.

Šafanda, J.: Ground surface temperature as a function of the slope angle, Tectonophysics, 360, 367-375, 1999.

Wegmann, M., Gudmundsson, G. H., and Haeberli, W.: Permafrost changes in rock walls and the retreat of Alpine glaciers: a thermal modelling approach, Permafrost Periglac. Process., 9, 2333, 1998.

Wieringa, J.: Representative roughness parameters for homogeneous terrain, Bound.-Lay. Meteorol., 63, 323-363, 1993.

Williams, P. and Smith, M.: The Ground Thermal Regime, Chap. 4, Cambridge University Press, Cambridge, 83-121, 1989.

Zhang, T.: Influence of the seasonal snow cover in the ground thermal regime: an overview, Rev. Geophys., 43, doi:10.1029/2004RG000157, 2005. 